NEGOTIATING SUCCESS OR SETTLING FOR LESS? DECONSTRUCTING THE UNDERACHIEVEMENT OF AFRO-CARIBBEAN YOUTH IN TORONTO HIGH SCHOOLS

by

Pasha Stennett, BA, University of Windsor, 2001

B Ed, OISE University of Toronto, 2003

\author{
A Major Research Paper \\ Presented to Ryerson University
}

In partial fulfillment of the requirements for the degree of

\author{
Master of Arts \\ In the Program of \\ Immigration and Settlement Studies
}

Toronto, Ontario, Canada, 2008

CPasha Stennett 2008 
I herby declare that I am the sole author of this major research paper.

I authorize Ryerson University to lend this paper to other institutions or individuals for the purpose of scholarly research.

\section{Signature}

I further authorize Ryerson University to reproduce this paper by photocopying or by other means, in total or in part, at the request of other institutions or individuals for the purpose of scholarly research.

Signature 


\title{
NEGOTITING SUCCESS OR SETTLING FOR LESS? DECONSTRUCTING THE UNDERACHILVEMENT OF AFRO-CARIBBEAN YOUTH IN TORONTO HIGH SCHOOLS
}

\author{
(C) Pasha Stennett, 2008 \\ Master of Arts \\ Immigration and Settlement Studies \\ Ryerson University
}

\begin{abstract}
The academic underachievement of students from the African Diaspora in Canadian schools is not a recent phenomenon. Afro-Caribbean students are reported to drop out of high schools in Toronto at disproportionate rates. To uncover the social forces that contribute to these problems this paper will examine Afro-Caribbean patterns of community formation and the issue of systemic racism in Canadian society operating as a barrier to academic success. At an even greater rate Portuguese youth are leaving school prematurely. But unlike with Afro-Caribbean students' racism is not an issue. Rather for the majority of Portuguese students in Canada the reasons behind chronic underachievement are rooted in the current education system, which views immigrants as different and the source of their own failure. This paper uncovers the subtle forms of racism that many underestimate and the huge role it plays in dictating the lives of many youth from the Black community.
\end{abstract}

Key words:

Afro-Caribbean; Portuguese; underachievement; Toronto schools; racism 
"If you have no confidence in self you are twice defeated in the race of life. With confidence you have won even before you have started." -Marcus Garvey

I would like to thank the many people who have supported me throughout the process of researching and writing this paper. First and foremost I would like to thank Dr. Alan Sears for his knowledge and expertise, as well as offering his advice when I had reached certain roadblocks during the development of this project. Dr Grace-Edward Galabuzi for his interesting insights regarding the two groups studied in this paper, they were well received and aided in the conclusion of this project. Also I would like to extend my greatest thanks to my family, particularly my mom who would always have a cup of green tea ready for me when I really needed a fix. My brother Abeko for taking the time to revise and edit my work even though at times I had to bribe you. My colleague Sayema and my friend Phyllis for also editing my work and offering their criticisms, it was much appreciated! Finally my friends and colleagues at work who kept reminding me of all the benefits of completing this process even though it was physically and mentally draining to balance a full-time job while completing a graduate programme. 
In loving memory of my dearest grandmother Lena May Barnett who passed on January $7^{\text {th }}$, 2008 at St Ann's Bay Hospital located in Jamaica. It is your strength and courage I admired the most and the lessons you have taught me that I will carry with me all the days of my life. 



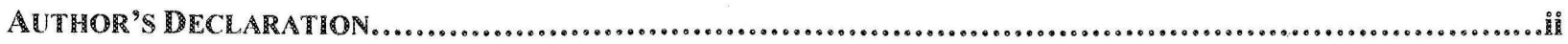

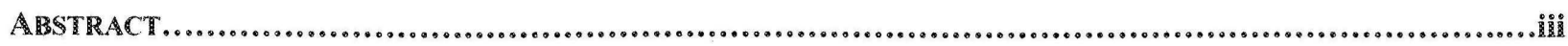

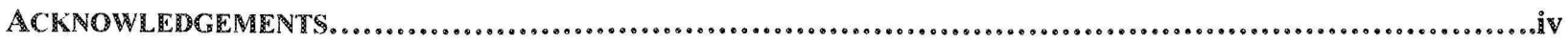

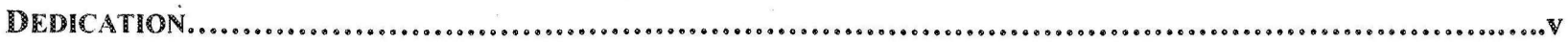

TABLE OF CONTENTS..................................................................................................vii

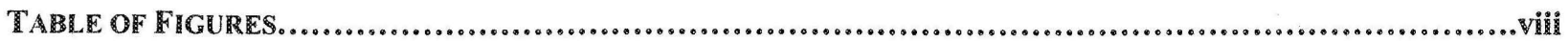

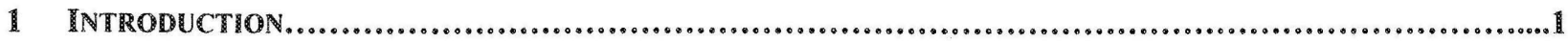

2 PATTERNS OF COMMUNITY FORMATION IN CANADA..........................................................5

3 The Five Dimensions of RACISM that IMPEDE AFro-CARIBbEAN YOUTHS PERFormanCE IN TORONTO

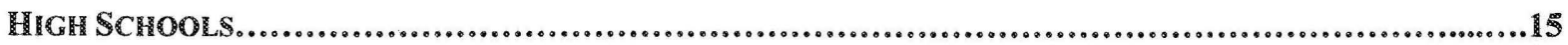

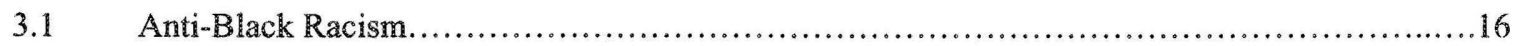

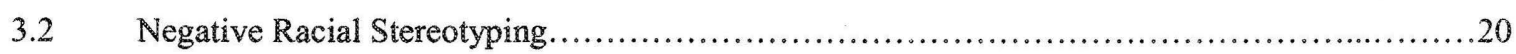

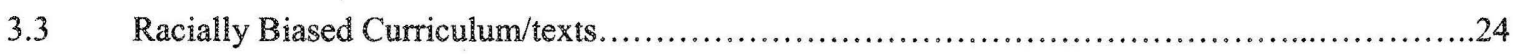

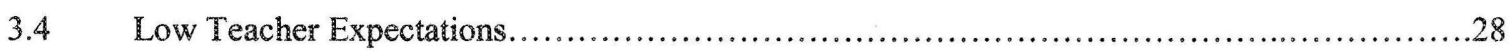

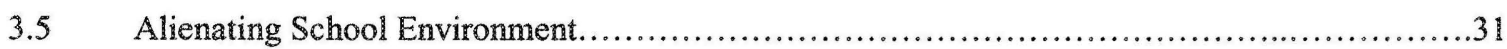

4 CASE Study: THE PORTuguese EXPERIENCE IN CANADA AND THE CAUSES BeHIND THEIR YOUTHS

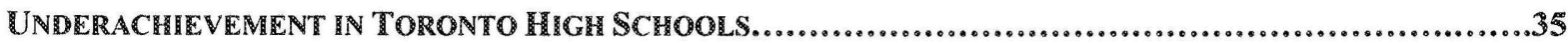

4.1 The Causes of Portuguese Students Underachievement in Toronto High Schools.....................38

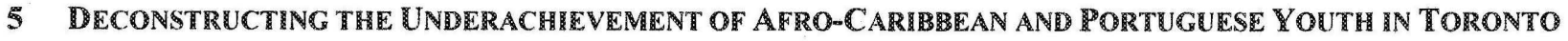

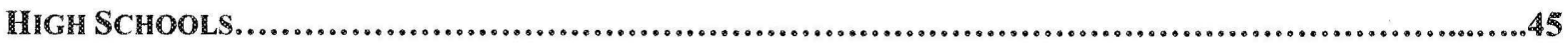

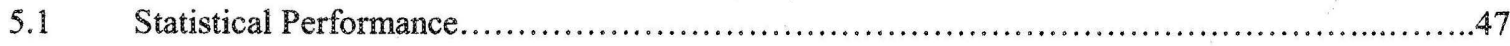

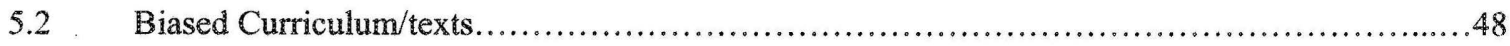

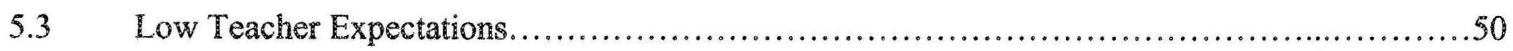

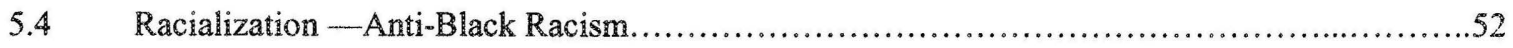

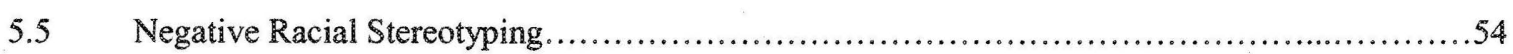

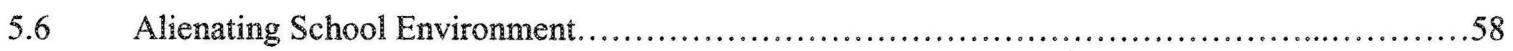

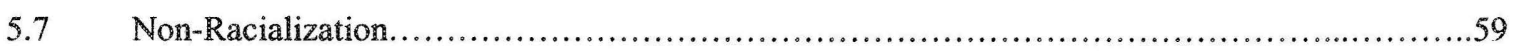

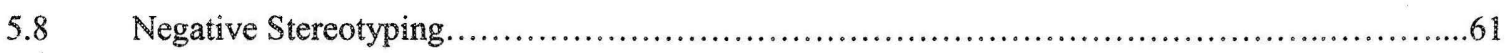

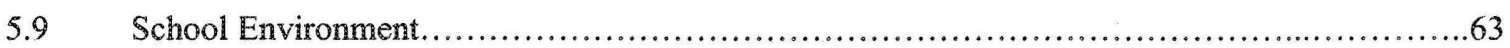

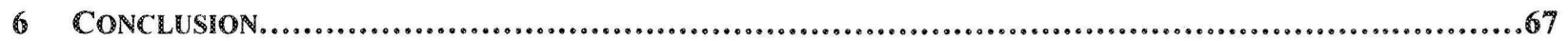

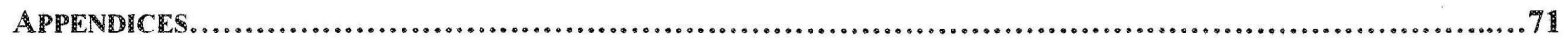

Appendix A - Jamaican and Trinidadian Settlement Patterns in Toronto and the GTA....................73

Appendix B - Portuguese Settlement Patterns in Toronto and the GTA...................................74

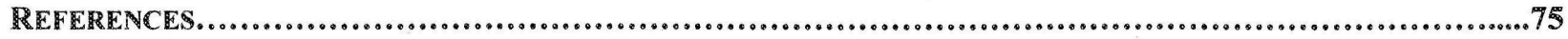




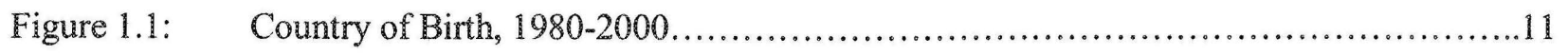

Figure 1.2: Country of Birth by Gender, 1980-2000 .........................................11

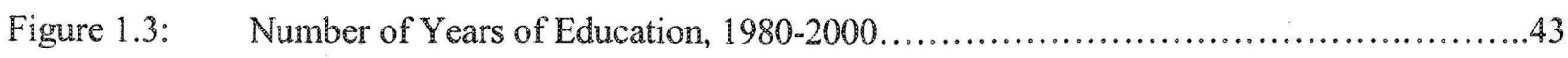

Figure 1.4: Country of Birth by Age, 1980-2000 ..........................................46 


\section{INTRODUCHON}

When one thinks of racism it is usually in the most blatant forms, which may range from images of lynching to the Klu Klux Klan. Canadians are often quick to reference the longstanding history of these practices that occurred in the deep south of the United States. Canadians from non-racialized groups often underestimate the power and complex nature of racism existing within institutions of Canadian society. For a White person to understand the complexity of racism and its effects on racialized groups they must acknowledge their own privileged status when comparing themselves to non-white groups. Canada's multicultural policies often serve to create a false impression of inclusion.

Similarly, when comparing many of Canada's early government policies to more recent ones the systemic nature of racism has gone from being overt to more subtle, manifested throughout various institutions. This is evident through one's social status in Canadian society, which is influenced by a number of factors that are closely related to immigration experiences and policies, including an individual or group's relationship to 'whiteness' and the specific moment of arrival in the country, all of which can determine the nature of community formation.

Our education system is also a further example of one of the many organizations in which the systemic nature of racism has disadvantaged many students from racialized groups. The complex impact of racism and racialization on school performance is often over looked. It has left a legacy of social problems that have impacted significantly on students from racialized groups such as Blacks who have lived in Canada for generations in addition to Afro-Caribbean and Continental African immigrants. Additionally students from ethno cultural groups such as Italians, Portuguese, and Greeks may encounter some educational inequalities in schools but their experiences greatly differ from the above groups because they are a part of a non-racialized group and are likely to be able to assimilate over some period of time and eventually gain acceptance and access to certain privileges due to their relationship to whiteness. The same however, is not true for Black students who face the robustness of whiteness in the system, which will continue to dictate the way in which they 'negotiate' their status for their entire lives. 
Essentially this paper will examine the dimensions of racism that Black students are faced with in the school system and how each one operates at such a complex level that at times may be difficult to demonstrate the weight of each issue. Another interesting aspect of this project will be the comparison of a racialized group with a non-racialized group in terms of similar school performance, which may cause some to question the need for schools to be restructured to reflect the changing demographics of Canada. Policy recommendations will also be offered in response to the issue of school performance as there is no simple solution to solving this problem since it relates to a multitude of factors, which makes it difficult to pin point a specific one.

In Canada there is a common misconception that the current education system is more inclusive than it has ever been and that different standards of achievement result from different community profiles not the exclusions that are built into the curriculum. The above occurrence is very relevant to students from racialized groups. However the primary focus of this paper will be the experiences of Afro-Caribbean youth and the exclusionary practices that have led to their chronic academic underachievement in Toronto high schools. The relationship between these two concepts will be examined through five dimensions of racism (anti-Black racism, negative racial stereotyping, racially biased curriculum/texts, low teacher expectations, and an alienating school environment) that were used by Codjoe (2001) in his research on the systemic racism that successful Black students encountered in Alberta's secondary schools. Drawing from the experiences of youth belonging to the Afro-Caribbean community and Codjoe's theoretical framework, each dimension of racism will be explored in terms of how each one operates as a significant barrier to the academic success of Black students.

Other students who do not come from racialized groups, such as those of Portuguese ancestry, also face certain barriers in Toronto schools. Their experience in the school system will be compared and contrasted with those experiences of Afro-Caribbean students who are challenged by the systemic nature of anti-Black racism. This comparison will be examined through the use of reports from the Toronto District School Board (TDSB), statistics, and current research, which will make connections to the five dimensions of racism and the immigrant experience.

For the most part many people have underestimated the complexities of racialization in education since it challenges our perception of inclusion in schools and Canada's identity as a 
multicultural society. As a result of this false impression of inclusion, racism is often overlooked and instead the community is held responsible for problems in education such as the alarming rate that Afro-Caribbean students are dropping out of Toronto high schools. Black parents and community leaders see this phenomenon as a major issue affecting the Afro-Caribbean community. Particularly, they are concerned that their youth are not "making the grade, and do not view education as a tool to achieve their life ambitions and dreams" (Dei 1994; For the Love of Learning 1994:8). Many Afro-Caribbean parents believe that if the underachievement of their children continues in Canadian schools, they will be in a far worse position than their parents who immigrated to the country.

This study will focus specifically on the experience of students of Afro-Caribbean background in Toronto's schools. For the most part, the majority of Blacks in Canada are of Caribbean origin (either first or second generation). Others have recently arrived from Africa, or have lived in Canada for generations (Simmons \& Plaza 1998). Subsequently, the highly educated and socially networked Caribbean migrants have played a pivotal role in Canadian community leadership (Simmons \& Plaza 1998). These better-educated and more affluent migrants have strengthened the presence of the Caribbean community's collective identity, social capital, and leadership potential in Canadian society (Simmons \& Plaza 1998). The passage of the Multicultural Act in 1988 has contributed to the visibility of the Caribbean community in Canada, even though earlier migrants in the community had been responsible for promoting antiracism initiatives prior to the passage of the Act. The activism of Afro-Caribbean immigrants, especially in Toronto, has made them a highly visible group that is continually studied and scrutinized by society. Other groups from the African Diaspora living in Canada have also been researched in terms of their academic performance in the school system and the research has indicated that the same systemic barriers have also contributed to some of the issues that youth face belonging to African/Black Canadian communities. However, more studies in this area are needed.

The paper will focus primarily on the Afro-Caribbean community rather than the broader experience of Caribbean communities of colour as the cultural patterns of peoples of IndoCaribbean and Chinese-Caribbean origins are different from those of Afro-Caribbean ancestry. The differences in cultural patterns between these groups are relevant in such areas as migration processes, family organization, kinship, and religion. Including research on the Indo - and 
Chinese - Caribbean community would require more in-depth research which is particularly difficult as the ethnicity of these migrants has been recorded inadequately in census and immigration data (Frances 1994). It is also important to clarify the meaning of 'A fro-Caribbean' and 'Black' that are used in my research (as it pertains to this paper). The term Afro-Caribbean is used to refer to Blacks from the Caribbean (mainly from Jamaica, Trinidad/Tobago, Barbados and Grenada) whereas the term "Black" has been used to refer to all individuals of African descent (i.e. continental 'Africans,' 'African-Canadian,' 'African-Caribbean,' and 'AfricanAmerican'). These two experiences have been distinguished to provide some context of how this issue may also affect youth in the broader Black community since it is assumed that we all share the same struggles, life experiences, and origin (Asante 1995:4; Henry 1993:219; Codjoe 2001).

Unquestionably, this is a very serious topic and worthy of study in order to create school systems that are inclusive and reflective of the values of all members and groups of society, which would in turn add to the increased scholastic success of "at risk" youth belonging to racialized and ethnic groups. Measures that would increase the likelihood of higher graduate rates for students of Afro-Caribbean background could evolve into more youth becoming positive role models in their communities and in turn contributing to the growth and development of the world around them. However, in order to gain further insight regarding the context of Portuguese and Afro-Caribbean communities' migration to Canada there must be an examination of the their presence in the country in relation to Canada's past immigration policies prior to 1967 and the impact these had on "non-white" migrants coming into the country. 
The immigration and settlement processes of various groups living in Canada are unique and diverse. The vast majority of immigrants that have migrated to Canada come here due to the weak economic conditions and social inequalities that exist in numerous regions of countries around the world. Those countries are often unable to utilize the labour power of their citizens. Many immigrants come to Canada with the intention of establishing a better life for themselves, and even more so, for their families. A developed country like Canada provides hope to new immigrants in the form of more opportunities. Worldwide, Canada is known to be a peaceful nation that is more receptive and respectful of people from diverse ethnicities. Overwhelmingly, the Canadian identity has become synonymous with multiculturalism. Indeed, immigration has greatly benefited Canadian society both socially and economically, however, the immigrant has not always been embraced by Canada (Jakubowski 1999). Previous immigration laws and policies were outright racist and only permitted a certain type of immigrant to gain entry and permanent settlement in Canada.

Past Canadian immigration policies restricted and excluded potential immigrants based on racial/ethnic characteristics from the 1880's onwards, (Hawkins 1989:16), whereas white British migrants were considered desirable and encouraged to relocate to Canada through extensive nation-building efforts undertaken by the government. Through the implementation of discriminatory immigration policies, both the English and French strengthened their position in Canada out of cultural and institutional domination (Alladin 1996:9). The Canadian government determined the criteria of previous immigration policies that resulted in the inability of ethnic minorities to settle in Canada prior to 1967 because they were from "least desirable" countries (Arat-Koç 1997). During the mid 1950's, however, a demand arose for unskilled and semiskilled labour that was deemed suitable for the "natural" abilities of people from SouthemEuropean descent: Italians, Portuguese, and Greeks. (Aguiar 2006:204). This labour market demand was a result of the Canadian government extensively recruiting temporary workers abroad from Southern Europe, even though these groups had been prohibited entry based on their 
supposed "biological eugenics" (not-quite-white skin) as much as for their supposed inability to integrate into Canadian society (Aguiar 2006:204). However, this kind of gesture cannot be mistaken for the government becoming "racially enlightened" towards Southern Europeans; rather such policies were explicitly created for assigning the most dangerous and least desirable jobs to these immigrants (Aguiar 2006:205). Therefore, immigration policy can be compared to a faucet that can be turned on and off according to perceived demands in the economy, which limited the extent to which visible and ethnic minorities could migrate and settle in Canada.

For this reason, past immigration policy can be characterized as systematically racist whereby institutions within society discriminate against individuals or groups of people they feel are undesirable or who are perceived to hold a subordinate position within society. The characteristics that are used to judge a particular group of people are often times "based not on the actual capacities of the [people], but stereotypical characteristics that have been ascribed to them because they are attributed to a racial minority group" (Gittens, Cole, Williams, SriGuggan Sri-Skanda, Tam, Ratushny, 1995:7). For example, Canada's definition of permanent citizen was framed on the basis of race, class, gender, and social relations. Initially, the word race surfaced in section $38(\mathrm{c})$ of the 1910 Immigration Act as grounds for a prohibited or restrictive legal classification (Jakubowski 1999:104). This section was later revised in 1919 to include "nationality," a crucial element of the "White Canada" policy which forbids the entrance of undesirable immigrants seeking passage to Canada as described below:

Any nationality or race of immigrants ... deemed unsuitable having regard to the climatic, industrial, social, educational, labour [conditions] ... or because such immigrants are deemed undesirable owing to their peculiar customs, habits, modes of life, methods of holding property and because of their probable inability to become readily assimilated or to assume duties and responsibilities of Canadian citizenship within a reasonable time after their entry (cited in Jakubowski 1999:104).

By explicitly stating whom the 'undesirables' were, section 38(c) of the Immigration Act amended in 1919 formally legislated the differential treatment of persons based on race or nationality in Canadian policy for the next fifty years (Hawkins 1989:17). Hence, Blacks and other non-white groups were stigmatized and viewed as undesirable by law, and not welcomed to Canada because they were not likely to assimilate and could prevent the construction of a homogenous nation of people who were similar in customs and ideals. 
Canada's Immigration Policy prior to the 1960's and government intervention strategies greatly hindered visible and ethnic minorities from gaining entry to Canada. These groups were considered inferior and unable to assimilate according to the pre-established norms and values of their British predecessors. This was especially true for groups of people who would later identify themselves as visible minorities such as Afro-Caribbean people. The continued restriction placed on Afro-Caribbean women from entering Canada was that these women (or any visible minority women) threatened nation-building efforts due to their reproductive capabilities and their presumed inability to rise to the moral character and qualities of their white British counterparts, who were deemed "Mothers of the nation" and therefore entitled to assume the role of motherhood for future generations of Canadians. It is worth noting that even though Canada may have legislated a very strict immigration policy against other "races," the government did not hesitate to recruit labourers from these "inferior" groups:

It is only when the Canadian economy desperately needed certain labourers, such as domestics, that Canada began to allow immigration from countries other than Britain. Yet, as the demographic composition of domestic migrants changed from predominantly white women to primarily women of colour, Canada's admission policies became more complex, eventually denying foreign domestics citizenship rights and social entitlements bestowed on other immigrants (Cohen1994: 83).

This employment strategy clearly exemplifies that the recruitment by Canada of Caribbean women through the second domestic scheme of 1955 was purely driven by labour market demands and not by policy makers becoming liberalized in their views of so-called undesirable immigrants. Clearly the Canadian government adopted discriminatory measures to keep out undesirables, in particular Afro-Caribbean and Southern European people, with the exception of situations wherein these groups were deemed suitable for labour market needs. In such cases they were readily accepted into the Canadian economy through contractual agreements to work for a particular employer in a specified field for a certain amount of time. In the case of domestics that arrived in Canada under the 1955 program they acquired "landed" status and became permanent residents of the country once they arrived via the programme although the government still reserved the right to deport any individuals who demonstrated traits that deemed them to be unsuitable for the programme (Cohen 1994:84).

Today's Live-in Caregiver Program, for instance, does not immediately admit domestic caregivers as permanent residents. Workers are required to complete two years of domestic 
service within three years of their arrival to the country and only then can they acquire permanency and citizenship (Citizenship \& Immigration Canada 1999:1). It is interesting to note that throughout the terms of the LCP contract, the immigrant status of caregivers remains intact as a temporary worker who is designated as a visitor in the country, which leaves the caregiver wide open for deportation (Arat-Koç: 1999). The majority of these women are from the Philippines (Citizenship \& Immigration Canada 2005).

These recruitment strategies have systemically disadvantaged various racial/ethnic groups of people by creating barriers that impede their progression in Canadian society due to the legacy that they leave behind. For the most part, in Canada, immigrants have been sought after as a source of cheap labour to subsidize the economic growth of the country. However, the conditions of their employment (the type of work they will perform and the wages they will receive) are closely related to their race, gender, and the source country of the immigrant. This process results in certain groups becoming naturalized with a specific type of work, which legitimizes their position in an occupation. Many immigrants that have migrated to Canada are highly skilled (nurses, teachers, etc.) in their countries. But when they come to Canada, they cannot gain employment in their previous occupations because their "foreign" credentials are not recognized in Canada or they may lack "Canadian experience" or be limited to the conditions of employment stated in their contractual agreement.

Upon further examination of the dimensions of race, gender, and country of origin, and how each one plays out in the societal sphere, one can conclude that the type of work that immigrants have been employed to perform also defines their worth to society. For example, Caribbean women were recruited and employed in the homes of middle class white women to provide domestic labour, by nature because it was considered to be "women's work." Gabriel (2006:165) states that this concept has been "socially constructed and connected to the gendered division of labour." The result is the salary that women receive in the paid labour force can be equated with their gender roles. Therefore, work in the public sphere that is connected to cleaning or providing support to others can be linked to unpaid domestic duties, which are considered household chores to be performed exclusively by women coming from developing countries. This type of work continues to be associated with women, in particular, immigrant women (now from the Philippines) because it is believed that domestic labour comes "naturally" 
to them and therefore should be defined as unskilled labour. A direct consequence of assigning labels to certain groups is that it further contributes to their undervalued position in society.

As a result of their parents' status in society, some children from racial and ethnocultural groups do not have a secure foundation in place with regards to the family unit. They are on various points of the spectrum and must work twice as hard as their White Canadian born counterparts to stay "afloat" in the school system (Kilbride \& Anisef 2001). One major factor contributing to the lack of academic success amongst marginalized youth is their inability to access social capital (Kilbride \& Anisef 2001). In the context of the family, social capital is created by parents and refers to "strong bonds with their children, formed through time spent in communication and trust building, and a sense of shared responsibility" (Kilbride 2000:4). This becomes apparent through parental involvement in their children's efforts at school in addition to the involvement of parents as a community dedicated to education (Kilbride 2000:4). Therefore, this theory focuses on the fact that certain relationships lead to an increased likelihood of success. In Canada, the National Council on Crime prevention states that it is "the protective network of supportive and positive relationships among children, parents, and families, social institutions, and all community members" (Kilbride \& Anisef 2001:20). The Council also mentioned the following findings:

When these relationships are strong and working effectively, they improve the ability of the community to meet the material, emotional, physical, mental, and spiritual needs of all its members. They also help people create opportunities and social institutions to reduce risk factors, isolation, and vulnerability in families and youth (Kilbride \& Anisef 2001:21).

Therefore, youth from racialized/non-racialized families may have limited social capital in Canada as family and friend networks may be spread internationally which places added pressure on parents to provide all the above-mentioned needs.

The above predicament is also a characteristic of the crisis that many second generation youth (those born in Canada) encountered when members of their family began migrating from the Caribbean to Canada and other parts of the world. Traditionally, Caribbean culture adopted and utilized migration as a survival strategy in response to the decline of older economic sectors such as sugar production and plantation agriculture, which were popular during the 1800's (Simmons \& Plaza 2006). The decline of these sectors had resulted in many individuals traveling to neighbouring islands and countries in search of work, which became a part of their 
livelihood for the families of many people. Eventually, travel destinations became farther away, which resulted in migrants spending more time abroad and eventually declaring foreign locations as permanent places of settlement (Simmons \& Plaza 2006). This practice was not uncommon amongst middle-class Afro-Caribbean women, many of whom migrated to Canada just prior to the 1960's. Henry (1994) states that the government recruited many of these women to be a part of the domestic labour scheme. These women established and led a wave of chain migration through which male partners; children and kin were then sponsored into Canada (Plaza 2003).

In addition, significant changes in Canadian immigration policy in 1967 led to a further increase of the Caribbean community in Canada. Subsequently, from the late 1960's through the mid 1970's, some eight to twelve thousand immigrants arrived each year from the Caribbean (Simmons \& Plaza 2006). These numbers of arrivals have varied throughout the decades that follow but the numbers reached a high in 1993, when more than twenty thousand Caribbean-born individuals arrived (See Figures 1.1 and 1.2) (Simmons \& Plaza: 2006). However in the period of 1998-2001 Caribbean immigration dropped dramatically to a reported estimate of eight to ten thousand immigrants who arrived each year (2001 Census data cited in Simmons \& Plaza 2006:137). These numbers are comparable to the patterns of immigration that were observed around 1980 (Simmons \& Plaza 2006). Consequently, the changes in Caribbean migration to Canada can be attributed to three factors: first, during the early to mid-1990's, Canada increased the educational and skills requirements for individuals arriving in the country under the independent class. Secondly, sponsors of family-class immigrants were required to have more financial income. Finally, American immigration policy had more open family-reunification features, which had encouraged Caribbean migrants to settle south of the border (Simmons \& Plaza 2006).

There are many factors that constitute the reason behind the previously mentioned migration patterns of the Caribbean community in Canada; they can be analyzed as push and pull factors. Some of the push factors that have contributed to large waves of Caribbean migrants coming to Canada were propelled by the structural adjustment policies requiring huge loan repayments that devastated the economies of Caribbean islands and many developing countries around the world. As a result, these countries were faced with high unemployment, low wages, crime, and poverty. The major pull factor was that many Caribbean people possessed the skills 
Figure 1.1 Country of Birth, 1980-2000.

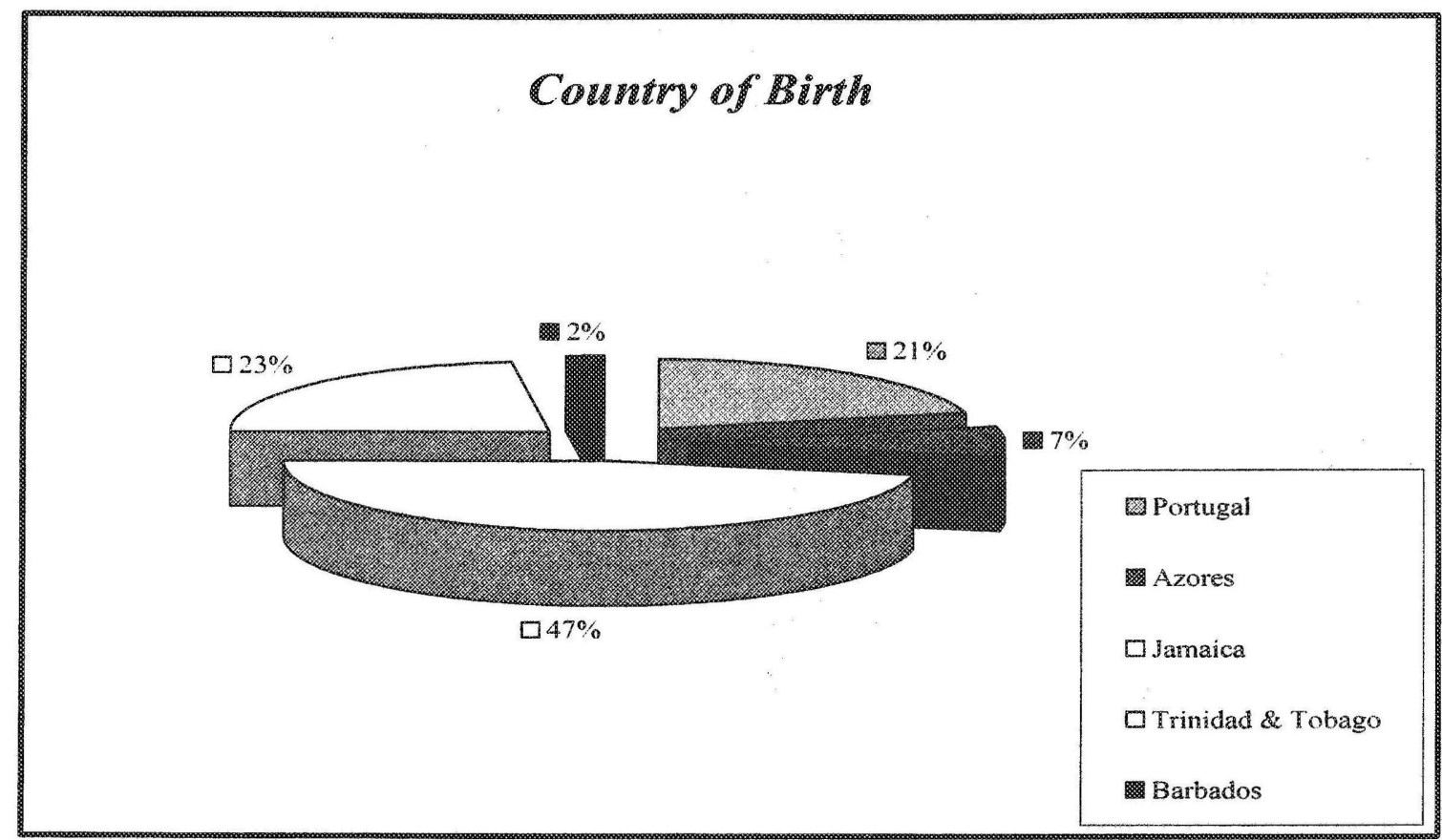

Data Source: Landed Immigrant Data System

Figure 1.2 Country of Birth by Gender, 1980-2000.

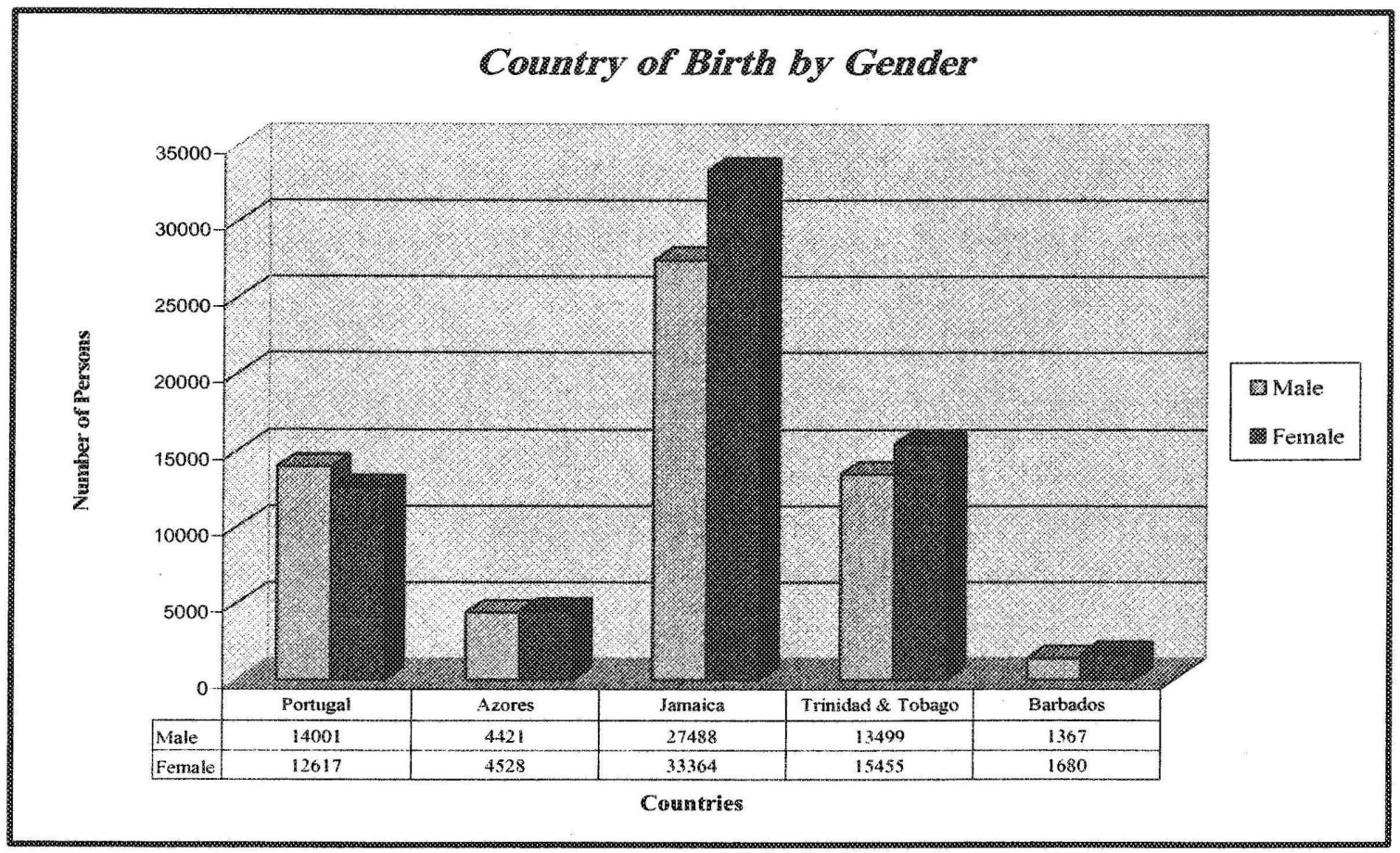

Data Source: Landed Immigrant Data System 
and attributes that were outlined in Canadian immigration policy selection criteria, such as the ability to speak English and or French, middle levels of schooling, and occupational skills (Refer to Figure 1.3) (Simmons \& Plaza 2006). Moreover, a significant proportion of Caribbean migrants (estimated to be $8 \%$ ) were university educated prior to their arrival in Canada (Simmons \& Plaza 2006). Some had acquired their degrees at Canadian universities and were well connected in the country.

People of Caribbean ancestry have also created two distinct residential concentrations of settlement in areas located within the city of Toronto as follows: Eglinton and Vaughan road and the Bathurst and Bloor area (Henry 1994). Once these initial communities became established, they soon were over crowded and people started to move into sections of Scarborough followed by suburban areas such as Brampton and Mississauga (Refer to Appendix A for the two largest groups from the Caribbean that have settled in various locations in Toronto and the GTA).

It is equally important to note that another form of community development was happening simultaneously to the one outlined above, but among the more disadvantaged members of the Afro-Caribbean community. Due to the increased demand for subsidized housing amongst the poor in the community, the Metropolitan Toronto Housing Authority developed neighbourhoods such as Jane and Finch, which are marked by a number of "people on welfare, mother's allowance, and other forms of subsistence" (Henry 1994:229). Such areas have been identified as "hot spots" wherein crime and the distribution of drugs are rampant. The constant police surveillance however that these areas come under is not necessarily a result of illegal activity but is due mainly to racial and community profiling by police officers. Yet despite the dreadful conditions discussed, these poor communities still provide a "sense of security and togetherness which people claim makes them feel comfortable" (Henry 1994:230). However, it can be argued that the MTHA's policy of placing Black people, who are predominantly of Caribbean decent, together in the same housing project, "creates the development of a Black underclass, which further divides the community, the majority of whom are among the respectable working class and middle class" (Henry 1994:21). As a result of this division, a segment of the Caribbean community becomes "stigmatized" which is brought about by systemic barriers that contribute to their marginalization and is stimulated by the negative racial images that hinder the social and economic mobility of those individuals from lower income levels (Henry 1994). This pattern of residential concentration amongst a segment of 
Afro-Caribbean people therefore creates educational concentration, as schools are community based. Subsequently their residential concentration in public housing increases their already subordinate position and contributes further to their "differential incorporation (which is defined in this context as the inability to access in full, the economic, social, and cultural rewards of society) into mainstream society" (Henry 1994:230).

A very important feature of Afro-Caribbean migration to Canada was the pattern of women immigrating without their families (particularly in the 1960's as domestics) and leaving their children behind to be taken care of by grandmothers, aunts, and other relatives while they were working abroad. As a result, within the Afro-Caribbean community, there are varied forms of living arrangements and family structures. Particularly, the absence of a father is not uncommon ( $42 \%$ of Afro-Caribbean families are headed by female lone parents) and families are loosely structured (Plaza 2003). This tendency should not imply that these families are dysfunctional since female-lone parent households predominate amongst working-class women in the Caribbean (Plaza 2003). However, one problem that the domestic scheme created for many of these women is that it required them to be single without dependents. Out of desperation, some women concealed their status as mothers to migrate to Canada for a better life. The practice of leaving children behind with caregivers was cited by Plaza (2003) as being prevalent amongst the Afro-Caribbean women who participated in interviews for his research. The above migration pattern can also be illustrated through the experience of a thirty-year old male named Mark who was sponsored by his mother in 1975 to come to Canada. Mark recalls this experience for Plaza:

My mom came to Toronto in 1971 or ' 72 . She then applied for my dad and he came in 1973 or 1974 . She was the first one in her family to leave Jamaica. She was looking for better economic conditions; maybe get a better job, a better education etc. I was a little baby when she left; I was only about nine months when my mother left. It was not until I was $5 \frac{1}{2}$ that I came to Canada. All that time I lived with my grandmother and actually I thought she was my mother (Mark) (Plaza 2003:16).

The above experience resulted from the conditions that were stipulated in the temporary employment visas that were issued to domestic workers. Some women were unable to see their children for as long as eight years. These women were filled with guilt and worry, but motivated by the hope and long-term dream of establishing a better life for their children (Burman 2002:61). However, many scholars believe that the domestic crisis of the absent mother is "a 
catch-22 scenario of Caribbean women leaving behind their children to work abroad, has had long lasting effects on children and mothers alike" (Crawford 2003:6). Further research and investigation are needed to address the gap in this area. Although Dr. Claudette CrawfordBrown, a professor at the University of the West Indies, had described the above phenomenon as the "barrel-children": "children [who] are left waiting in the Caribbean to migrate to their parents in the metropolis of North America and United Kingdom [and receive] material resources in the form of food and expensive consumer items like brand-name sneakers in lieu of direct care" (Crawford-Brown 1999).

The impact on these displaced children in Canada and elsewhere often varies depending upon the number of years of separation and the age at which the child is reunited with the mother. Many Caribbean domestic workers felt the urgency to partake in business marriages in order to speed up the process of reunification, because some immigration officials used a Eurocentric middle-class nuclear family as a reference point to constitute the validity of sponsoring dependents (Crawford 2003:5). It is worth noting that sponsorship did not guarantee that the reunification process between child and mother would be a smooth transition. The complexities of the migration process have resulted in habitual customs, values, and attitudes brought from "home" being altered in response to new hierarchies, cultural conceptions, and social institutions that are encountered in Canada (Plaza 2003). Therefore the lives of many Caribbean women who have migrated to Canada under the domestic scheme have been impacted on multiple levels affecting numerous individuals, including their children. Uitimately, the reason many Caribbean people choose to migrate "abroad" was to escape poverty, unemployment, limited opportunities, and the devastation caused by structural adjustment policies. But the opportunity to migrate came at an unfortunate expense of leaving children behind and vulnerability to an array of emotional, behavioural, and social disorders which leave them fragile and unable to develop some resiliency to battle the institutional racism they will encounter once they arrive in Canada, where they are viewed through a multitude of "gazes" that have been socially constructed through history, media, and government policies. These so called "gazes" can also be extended to second and even third generations of Afro-Caribbean youth who were born in Canada and know no other place to be home. Only through references made by parents and even grandparents do these youth hear of life "back home" in the Caribbean. 


\section{The Five Dimensions of Racism that Impede Afro-Caribiean Youths' PERFORMANCE IN TORONTO HIGH SCHOOLS}

Not only have patterns of immigration and community formation greatly impacted racialized groups, but also the subtleties of racism that are embedded within the education system. The African American experience demonstrates how robust racism can be when it has manifested itself within societal institutions such as schools. As a result of the systemic nature of racism in schools many African Americans have not acquired high levels of education, which has led to intergenerational poverty and further contributed to the low socio-economic status of many Blacks living in America. Therefore one must question the repercussions of such robust racism experienced by African Americans, and its relevancy to the Canadian context since the racial and ethnic composition of Canada has changed dramatically over the years. In the city of Toronto, it is estimated that immigrants comprise almost fifty percent of the population and increasingly, suburban populations in the Greater Toronto Area (GTA) are also transforming. Census data released in March of 2007 illustrated that Milton ranked number one in Canada with the highest growth rate in population of 71.4 percent between the years 2001-2006 (Canadian Press 2007). Although particular racial/ethnic groups were not specified as migrating to this community, it is more than likely that members from these groups can be accounted into this number given the diversity of the population in the City of Toronto and the GTA, in addition to immigration trends.

This diversity is also reflected in the classrooms of our schools that have become an international display of cultures. Administrators, teachers, and parents are all aware of the diverse nature of schools and have attempted to respond to the needs of such a complex student body. Unfortunately, the current education system is unable to cope with the rapid changes that have occurred in contemporary society (Alladin 1996:4). Institutional barriers towards occupational and social mobility have produced an extremely stratified society, whereby power dynamics are defined in terms of race, class, and gender (see, for example, Li 1988; Alladin 1996:4). In societies such as Canada, institutional racism has prohibited the social and financial 
progression of minority groups (Alladin 1996:4). In schools, these same practices may arise through the act of racialization, whereby administrators, teachers, and support staff consciously or unconsciously formulate preconceived beliefs about students based on their race (Henry 1994). The issue of racism being systemic in Canadian society will be addressed in that it has manifested itself in the structure and organization of schools. Presently, the education system in Canada continues to de-emphasize instructional methods that liberate minority groups, but continues to serve and reproduce the ideologies of the dominant culture (Alladin 1999:4). The classroom has become a tool that is used largely to uphold "and legitimize the status quo" (McCathy 1993; Alladin 1999:5). Minority groups, therefore, occupy lower positions within society due to their economic and social disadvantages that are rooted in the daily racism they confront which keeps certain racial/ethnic communities marginalized.

\subsection{ANTI-BLACK RACISM}

Anti-Black racism can be defined as behaviours or attitudes that are hostile or opposed to Black people. The actions of this particular racialized barrier may ultimately result in Blacks occupying a subordinate position or status in Canadian society. Instances of racism or racist attitudes, however, may range from subtle to overt messages that are embedded within the daily practices of our schools that adversely effect students' experiences such as name-calling, racial hostility, slurs, prejudice, and discrimination (Codjoe 2001:360). Some Afro-Caribbean students also implied there was a double standard for this specific barrier. They were aggravated to witness the occurrence of no consequences being given to White students that engaged in "racist language" or actions (Dei 1995: 44).

The onset of Black immigrants arriving in Canada, particularly Toronto and Montreal can be greatly attributed to Canada adopting a more liberal Immigration policy in 1967 (Calliste 1996). From the period of 1963-67, 23,316 Caribbean immigrants entered the country compared to 86,981 during the period of 1968-73 (Calliste 1996:92). These numbers reveal that the cultural climate of major cities such as Toronto was changing considerably. But despite the inception of a liberal immigration policy the continual everyday practices of racism that persons belonging to racialized groups experience are quite evident in Canadian society. Many AfroCaribbean youth (and even Canadian born Black youth) that had migrated to Canada during the seventies and into the eighties recounted many instances of racism that were present and 
operating in Toronto high schools. The personal accounts of these students most often referenced "name calling" as one of the incidents of racism that they had faced. For example, a grade ten student at the time, named Veronica had this to say, "I don't associate with Whites because they wouldn't associate with us and they'll call you 'nigger' right to your face." Veronica also mentions that at that particular time she had no idea what it meant for another student to call her a "nigger." She then continues to explain the incident as follows:

I looked at them and I said, 'Excuse me, what does that mean?' They just looked at my colour, so I just kept doing my work. Then I translated it to Jamaican, for in Jamaica they would say 'neager' and then I found out it meant 'nigger.'.. I slapped him down and I got into trouble.

The teacher asked me what I was doing. I said he called me 'nigger' and I don't like that and nobody is going to get away with that. The teacher said, 'What's the matter if he calls you nigger?' I said, 'Hey excuse me, would you like if I called you honky? He just looked at me. I said, "Now you know how it feels,' and I just sat back down (Henry 1994:137).

This incident above demonstrates one of the most overt forms of racism that earlier AfroCaribbean students encountered in schools. The fact that the teacher did not take any disciplinary action by assigning a consequence to the student for his inappropriate behaviour reinforces Veronica's devalued position in the classroom. The teachers' actions also makes it quite clear that it is acceptable to call individuals that are "different" derogatory names so long as they're not White.

Overt forms of racial hostility such as name-calling/racist graffiti were frequent occurrences for many Afro-Caribbean students primarily due to their small numbers, which increased their "visibility" in schools that were predominately white. Some students also mentioned that, "guidance counsellors would make references such as 'people like you' need to learn Canadian geography" (Henry 1994:137). Black students were also subjected to violence (beaten up) by their white counterparts; however when Black youth retaliated they "... would get into trouble from the school..." and were thought to be the ones who created the problem (Henry 1994:137). Subtle forms of racism could be observed through the tendency of teachers to perceive Caribbean students as the "other," because the groups "they" hang out in are loud (Henry 1994:141). Students however, assembled in these groups due to their continued exclusion from school life and activities. Schools often interpreted these sub cultural groups as an expression of Black militancy and therefore "discouraged" or rejected the "formation" of 
Black-based cultural groups (Henry 1994:123). It is quite evident that these groups developed in response to counteract the hostility, loneliness, and isolation that earlier Afro-Caribbean students' faced. They were placed at the bottom of the hierarchy in schools because they were perceived as incapable of conforming to white-middle class standards encountered in the education system.

Equally as damaging and even more hurtful is the intra-group discrimination and prejudices that peers elicit towards students who speak with distinct accents and dialects (Dei 1995:13). For example, the following incident describes how a male student was ridiculed by "fellow" Caribbean students for being a "freshie": "I didn't know why, so a couple of years afterwards I got to know that it was because I come from Jamaica and I wasn't into clothes and stuff that they were wearing. So after I got a job, I started dressing and getting into the situation" (Henry 1994:133). Black youth born and partially educated in the Caribbean and in Canada occupy a "marginal" position within intra-group dynamics because they are not considered entirely Caribbean or entirely Canadian (Simmons \& Plaza 2006).

These experiences were faced by earlier Caribbean immigrants and continue to be an issue for many Black youth in the current education system. These youth are caught between mainstream Canadian culture and the transnational Caribbean culture of their parents and relatives. Youth attempt to overcome their battle with their marginal identity through various behaviours. During late adolescence, some second-generation youth may assimilate an identity and path closely aligned with the host culture, however this choice is fairly risky and youth are often prone to rejection from Canadian society with no strong support group (Simmons \& Plaza 2006:143). Black students that have adopted behaviours that are considered "White" may face being labelled as "white washed" or "Oreo cookie" because they have chosen to resist intragroup expectations of black cultural identity (Henry 1994:145). Some re-establish their identity (this was evident in the "freshie" example) by fusing together traditional Caribbean cultural ideologies and practices that are evident in the everyday lives of family, friends, and the community. Many Afro-Caribbean youth will begin this process through "engagement with Caribbean art, music, food, dress, religion, social norms, myths, customs, and language (i.e. accents and sayings)" (Simmons \& Plaza 2006:143). This alternative is favoured by some AfroCaribbean youth because their parents' culture provides comfort and community support that 
will aid in their efforts to overcome the marginalization they are confronted within Canadian society (Simmons \& Plaza 2006).

Yet others have chosen to identify with Black American Hip Hop culture despite their Caribbean heritage. For many marginalized youth, Hip Hop culture speaks to them because it is considered to be the music of those left behind in improvised neighbourhoods that have created an underclass of groups living in ghetto-like conditions in cities such as New York City and Los Angeles (Simmons \& Plaza 2006). Hip Hop music and culture therefore, speaks and appeals not only to Afro-Caribbean youth but to one unified culture of youth from various racialized groups that do not identify with mainstream Canadian culture (Simmons \& Plaza 2006:143).

The above process is quite common and an essential stage in adolescent development which psychologist Erickson referred to as identity versus role confusion. Second-generation youth face a dilemma; they are caught between their parents' home culture and mainstream culture. In response to this dilemma, youth incorporate numerous pieces from their parents' culture and the social world that aid in the process of formulating an overall identity that will gain approval from their peers and be widely accepted by the dominant culture. Simmons and Plaza (2006) have stated that youth of Caribbean origin develop "segmented identities," however, this concept holds true for any second-generation youth seeking approval from their peers and the host culture (p. 143). In the case of Caribbean youth, these segmented identities are apparent during "language-code switching," whereby youth communicate in "proper" English when they speak to teachers and authority figures, but change to slang, patois, or other forms of Caribbean dialects in conversion with family and close friends (Simmons \& Plaza 2006). It is very apparent that youth in the Caribbean community have developed these "hybrid identities" under the presumption that "one code" helps enhance their integration within Canadian society, and will loan itself access to employment, institutions, and a better style of living, while the "other code" fosters the development of a network of friends and community support (Simmons \& Plaza 2006). In sum, Caribbean youth have come to the conclusion that the host culture may hold prejudicial views of their language ability based on stereotypes of black speech, which can lead to discrimination in various institutional settings such as the school system. In order to cope with this problem, Caribbean youth develop a "survival" identity that is used to interact with authority figures and mainstream society. 


\subsection{NEGATIVE RACIAL STEREOTYPING}

Adding equally to their frustration and viewed as a barrier to their academic success, Afro-Caribbean students are continuously defined by negative labels and social constructions of 'blackness' that are based on stereotypes of Black people. Students' experiences in Toronto schools echoed the following harmful encounters that they had with administrators, teachers, and support staff who assigned social and intellectual inferiority stigmas', streamed or tracked students, and finally, viewed 'Black' students as troublemakers.

Since Afro-Caribbean immigrants continued to migrate to Canada in large numbers, their children encountered many difficulties in the school system. One was their poor performance in schools, which some educators believed stemmed from their adjustment problems (James \& Brathwaite 1996:15). Other explanations used to describe Black youth had a tendency to be pathological (James \& Brathwaite 1996:15). Educators labelled Afro-Caribbean youth as being slow learners or learning disabled, possessing psychological problems, suffering from attention deficit disorder (ADD) or being hyperactive (James \& Brathwaite 1996:15-16). These labels resulted in many students being placed in special education classes and educators did not have to take responsibility for the failures of Afro-Caribbean students because they transferred the blame to the parents and the community (James \& Brathwaite 1996:16). The same explanations however does not hold true for Canadian-born Black students who did not fare well in school and had parents that were very supportive of their academic endeavours (James \& Brathwaite 1996:16). Generally speaking, education is valued in the Black community and is viewed as a means of getting ahead and achieving your goals and aspirations in life, especially in countries such as Canada where race may be a barrier to your success. Therefore, educational credentials will provide unlimited opportunities. Henry (1994) states that:

Caribbean parents place an inordinately high value on education, which is important in its own right and is also considered the only avenue of mobility for people from the lower social class. Even poor single mothers will do their utmost to ensure that their children receive as much schooling as possible. Their efforts to make sure their children have at least one clean uniform and one pair of shoes are legion (p. 126).

The example given above demonstrates the dedication and support that Black parents provide for their children when it comes to their schooling. Despite their socio- economic status, they value education and view it as a tool for their children to improve their social status in 
society. These same principles are still very strong and entrenched in the belief systems of Afrom Caribbean parents in Canada. A detriment to Afro-Caribbean youth in Toronto schools however stems largely from the negative social constructions (stereotypes) of Black people in society, which are associated with these youth in the school system and operate as a barrier for them to realize their educational goals (James \& Brathwaite 1996:16).

A study completed by Dei (1995) found that students educated in the Caribbean voiced concerns that Black students were being socially labelled as "trouble makers" (p. 13). A further troubling issue that students complained about was that the Black male is stereotyped as "violent," and a "criminal." The students felt that the media had a lot to do with these misconceptions and should be blamed (Dei 1997:116). Black female students also pointed out that their male counterparts were at more of a disadvantage in the education system due to their gender and the heavy surveillance they are placed under especially for disciplinary actions (Dei 1997). A female participant from Dei's study had this to say:

I think Black males have it harder because they're stereotyped, they're all bad. . . . Like they see a couple who are just like messing around, or whatever, and ... not that there are some people over here who are doing good. . . It's not fair. I don't know why they just can't treat the person who's doing good, treat him, don't just keep putting him down or whatever, and don't put the people who are doing bad down. Tell them, "you shouldn't be doing this." Talk to them, and not just, "go down to the office." [But] then they suspend them. I mean, that doesn't do anything. You're just doing a favour for them (1995:50; Spence 1999:81).

Even when Blacks males make positive contributions to the social climate of schools their behaviour is not recognized and they continue to be looked down upon by teachers:

If I was White... with the athletic stuff that I did... I would have got so much recognition more at school than if I was Black. Even though I did do well in that, there was still a negative side towards it that was pinned on me. No matter how good you did there was still that part of you, well, you know, "He does get in trouble sometimes." If I was a White kid they would overlook that... (Dei 1995:43).

Given the two examples mentioned above with regards to perceptions of Black males in schools, one can draw a parallel to schools mirroring the world outside the classroom. Just because one may be a teacher it does not imply that they are free from gender stereotyping. It is quite evident that these beliefs and practices are apart of the current school system. 
Another issue of great concern to many parents is the fact that despite their efforts to encourage their children to pursue high levels of education they feed into social stigmas of becoming "entertainers" or "athletes." Since teachers are apart of the socialization process that occurs in schools, the lack of achievement amongst Black students can be examined at this level. There is evidence that indicates some teachers are responsible for discouraging students' interests in other ventures and streaming Black students into athletic activities (Calliste 1996:18). For example a teacher by the name of Ed from Spence's (1999) study had this to say, $\because$ traditionally, teachers stereotype Black kids as athletes and recruit them for athletic teams. As a result, Black kids are encouraged more in that domain" (p. 81). Blacks are discouraged from pursuing academics because they are associated with stigmas of intellectual inferiority. For instance, a student in Henry's study (1994) of Afro-Caribbean students describes a situation wherein a Black male and female are enrolled in a grade ten science class and in the middle of a lesson the teacher states the following: "Oh, I see we have two coloured students in the class. It's been my experience that coloured students don't do too well in the sciences" (p. 138). Despite this occurrence may have been during earlier periods of Caribbean migration it is still very relevant. In the current school system, teachers may or may not communicate their thoughts as overtly but many Black students are aware of the fact that some teachers' measure their abilities by associating their race with specific stereotypes that leads to low expectations being connected to all Black students. This can be observed through the following account:

I feel so angry; I get so bitter inside for them because it's like this is what people expect of some Black people, that they can't accomplish nothing. They can't be a doctor or a lawyer...they're not capable. They're ignorant, as 'they' put it. They always say we're ignorant, and it just, it makes us look so low (Dei 1995:23).

The anger that has been expressed by this student reveals that he/she is frustrated with the fact that teachers or guidance counsellors have already predetermined the position that Black students should occupy in society and there is nothing he/she can do to resolve this problem.

Next, the practice of streaming and tracking students has been a huge concern for parents of Black children because this process determines the educational opportunities that are available to them upon graduating high school. Some believe the practice of streaming is evident when stereotyping and labelling become "formalized" within the education system (Dei 1997:115). Often times, minority or working-class students have been targeted and placed in the lowest academic streams, which operates as a barrier to improving their "social status through the 
educational system" (Dei 1997:116). The following occurrence can be demonstrated through the past experience of a student:

$\ldots$ in grade 8 , I went to a majority Black school. Our guidance counsellor was telling, 'Well, when I look at your faces, I could see that not many of you are going to be going to university. So there's no reason why you should be taking advanced. What you should do is just stick to the general and basic.' That's what he was telling a group of us. There were a lot of us there. And so, it's like the guidance counsellors and the teachers and everybody, they just push you into the basic courses. And then, there's nothing after basic. You don't realize that until you get to grade 12. You know you can't do nothing with that ...(Dei 1997:118).

The above example provides an illustration of Black students not being given the opportunity to plan for their own future, it is predetermined with very little input from students who later come to the realization that they are unable to pursue their career aspirations because they were forced to take non-academic courses that lead to dead-end jobs (James \& Brathwaite 1996:17). As a result, some may lose interest in school and dropout or be steered into certain careers. This is evident in the following instance whereby a student by the name of Damion states:

We do [sport] because I guess we think it's the only way we can get ahead. We've seen it happen before, and it's the only way for us to get ahead. If you do take the academic way, it is very hard because you know the teacher doesn't think you can do it with your brains (Spence 1999:76).

This statement is loaded with many of the subtle messages that students have to confront in the school system and their daily lives. For Damion to reflect on the world around him and come to the conclusion that there are "limited" opportunities outside of sports means he has conformed to the stereotypical images of a successful black male. This results in Damion and other groups of students not viewing academics as a valid path to achieve success because the only place they have witness success in society is through the sports and entertainment industry.

Finally, Afro-Caribbean students have voiced many concerns for the unfair treatment they have received because their cultural and linguistic differences were used to place them in English-as-a second-language (ESL) or English-skills development (ESD) classes (Dei 1997:118-119). Despite being schooled in English in the Caribbean, the Canadian education system believed that these students were deficient in their language abilities and therefore placed them according to the above mentioned streams or put them back a year (Dei 1997:118-119). Students that went through this experience were extremely upset to be in a class with a younger 
sibling or to have to redo things they had previously done in their home country (Dei 1997:119). It is quite apparent that the school system has the authority to determine the academic stream of students by attaching negative evaluations to students based on language characteristics such as speaking with a non-Canadian accent (Dei 1997:119). This can prove to be detrimental to youth that belong to racialized groups because in order for them to make it in the school system they must conform to White middle-class cultural norms and standards of language acquisition. The purpose of the school system therefore is to transcend dominant cultural standards to immigrant and racialized youth in an attempt to canadianize them however the ramifications of these efforts can prove to be life long for those individuals that are not able or unwilling to conform (Dei 1997:119).

\subsection{RACIALLY BIASED CURRICULUM/TEXTS}

This barrier has been a struggle for Blacks in Canada over 100 years and continues to be debated into the twenty-second century (Calliste 1996:90). Inclusion in school curriculum means that the lived experiences and contributions of persons of African decent as well as other groups should be reflected in the classroom for all students to benefit from the process of learning (Calliste 1996:91). Afro-Caribbean students repeatedly reported that their disengagement from school courses stemmed from the little relevancy it had to their lives. Some questioned the level of Eurocentric bias present in the curriculum content and textbooks.

The type of education that Black students receive in Canada has been a very contentious issue. Ibrahim (1996) states "textbooks and educational materials that present erroneous information about certain racial groups or omit their contributions are other examples of institutional racism" (p. 12). This problem along with a high dropout rate amongst Black youth has led to a proposed Black Focused school that will open fall 2009 in the Toronto District School Board (TDSB). James and Brathwaite (1996) have noted that "the curriculum concerns are some of the most damaging elements in our schools' schooling, and this is an area that has attracted much attention in the Black community among educators" (p. 29). In the past and at the present, the school curriculum has been faulted as a barrier to Black students' success (James \& Brathwaite 1996:29). Many Black youth feel they are being robbed of their history because current teaching practices deny the existence of the Black experience in Canada. Students' narratives echoed constant themes that they were unable to connect the curriculum to their own 
lives and therefore find it difficult to relate to the educational experience (Dei 1997:137). For example a student by the name of Denise who dropped out and then took an African History class upon her return to school mentioned how the course was structured prior to her dropping out:

The curriculum ... was one-sided, especially when it came down to history. There was never a mention of any Black people that have contributed to society ... I mean, everything, it's the White man that did. History is just based on the European Canadian that came over ... There was no mention of the Africans that helped build a railway, that ran away from the south and came up to Nova Soctia and helped work and build Canada too ... no mention of that (Dei 1997:138).

This quote is a primary example of what many Black youth and other groups must confront in the classroom each day: the absence of their particular racial/ethnic group in the school curriculum. Denise notes the fact that the presence of Blacks in Canada is not acknowledged in her Canadian history class, which sends a message to Black students, that there contribution is insignificant and they are not true Canadians. This further implies that the contributions of Blacks/African Canadians are not seen as inherent to the development of Canada. Therefore anyone not belonging to one of the "founding groups" (Britain and France) in Canada is excluded from the curriculum, particularly Canadian history. Some teachers agreed with this practice and felt no obligation to include other groups in the curriculum because it was unnatural (Dei 1997:139). Dei (1997) states that these individuals:

expressed the sediment that inclusive education was simply a response to pressures of 'political correctness' and felt that the curriculum should reflect Canada, implying that Canadian history basically went back to European contact and that the 'minority presence' is recent and peripheral (p. 139).

This belief expressed by teachers in the Toronto school board demonstrates the value that is placed on Eurocentric curriculum. All students' therefore are forced to identify with traditional standards because they are perceived to be enough. During this process of "learning" students experiences are being excluded which results in them losing interest in school and even contemplating the possibility of dropping out.

A further way in which teachers exclude the interests and experiences of students belonging to racialized groups is by dismissing discussion on controversial topics or social issues that these students face in society. This is evident in the following example where a teacher stated, "We won't talk about the Rodney King incident, because I don't know about it," and then 
decided to chat about sports (Dei 1997:130). This is a very damaging statement for students that can identify with the incident. The fact that the teacher has acknowledged the occurrence demonstrates that they know about it but may feel uncomfortable about discussing it. Apart of the responsibility of a teacher is to engage students in the process of learning by making lessons relevant to their real life experiences or interests. Students who perceived certain teachers as doing the least amount of work required (text book exercises) in the classroom were not actively engaged in the learning experience and therefore did not put forth their best effort academically (Dei 1997:130). It is quite apparent that the actions of teachers speak volumes to students, these subtle messages reaffirms whose interests are valued and therefore reflected in the discourse of the classroom. Equally important to note is the degree of cultural insensitivity that is demonstrated by a number of teachers and can be revealed through comments made by a student named Susan: "She said to the whole class, that AIDS came from Africa ... and like, there's all this kind of proof' (Dei 1997:130). These types of comments or actions further distances Black students from the classroom experience because the only time they do get a glimpse of themselves is in a negative instance which reinforces their devalued position in the classroom.

Another issue that students brought up was the fact that teachers discouraged students from examining curriculum critically especially if their statements referenced racism or Eurocentrism being present in such books as Lord of the Flies and Huckleberry Finn were amongst those that Black students disliked (Dei 1997:131). A student by the name of Sandy describes a disagreement she had with a teacher over this particular issue:

I had to do an essay on Huckleberry Finn and Roots, and I was writing that I thought Huck was racist just because of the things he said, and I backed it up and everything. And because I said that, [the teacher] didn't like it and gave me a really bad mark. And when I went to talk to him about it, he said, 'No, you can't say Huck was a racist because he became friends with Jim'... I told him that the book offended me and he was, like, 'This book did not offend.' (Dei 1997:131).

This persistent attitude displayed by some teachers to dismiss discussions revolving around attitudes on race and Eurocentrism being imbedded in the curriculum only works against the interest of Black students and other racialized groups. The entire student narratives reveal that in order for students to be engaged in learning, an equitable classroom environment must be created that legitimates the lived experiences and concerns of every student (Dei 1997:131). Learning is a reciprocal process whereby the student and teacher work as a collective to examine 
various course materials critically in order to develop their ability to challenge and redefine the knowledge that has been presented to them (Dei 1997). Therefore, teachers who steer clear of employing the above practice in the classroom environment are actually doing their students a disservice by discouraging them to be critically conscious of their surroundings.

In response to the disenchantment towards a Eurocentric curriculum many Black parents and community leaders advocated for change that would improve the academic performance of their children in the education system. The seventies became an era of dramatic changes in education. School boards across the country adopted multicultural policies following the establishment of Canada's Multicultural Policy in 1971 (James \& Brathwaite 1996:23). By the late seventies Black History Month programmes were implemented in Canadian schools to foster sensitivity and respect for cultural differences as well as to integrate the "minority" student (James \& Brathwaite 1996:25). The Black community and parents have come to regard these programmes as inefficient in tackling the education needs and situation of Black youth (James \& Brathwaite 1996:25). The multicultural approach to education has come under scrutiny and criticism by many in the Black community as a celebration 'focused on 'song and dance,' stereotypes or 'museum culture,' and 'other' Canadians-immigrants with a foreign culture" (James \& Brathwaite 1996:24). Many believe it does not address the real issues that non-white groups face in Canada such as racism and social inequalities. Equally important to note is the manner in which knowledge about Black History Month is disseminated or compartmentalized into a separate month existing outside of Canadian History. The structure of this programme needs to be revisited it reaffirms the undervalued position of Blacks and other groups that their experiences and contributions can be taught as isolated incidences to restore "Black Pride" or "Cultural Pride" amongst students for a short time and then revert back to the regular curriculum routine (Prince 1996:176). Prince (1996) states history needs "...to be taught as parts of world history" which would result in links being made to a chain of historical developments that are all interconnected to one another (p. 176). The boredom and disconnect that students undergo with the curriculum can be heard through the account of a student named Richard that states:

I am not sure that some stuff we're taught is relevant. I'm sure I'd be a lot more interested if there was some more Black stuff to read about. Now that interests me-brothers like Malcolm X and Martin Luther King. We don't talk about them much, except February. But I hear a whole lot about Columbus, Mackenzie King and those explorers (Spence 1999:76-77). 
This response conveys a common feeling amongst Blacks and other students. Their lack of representation in the curriculum can be closely associated with the invisibility many experience in a school system that is unresponsive to their needs (Dei 1997:145). As Dei (1997) states, the current school system continues to reinforce "the power and privilege of White Society, and contributing, in a sense, to the colonization of other knowledge's and experiences" (p. 146). This is evident through Michelle's account below of the school system purpose is to strip students of their identity and re-assimilate them according to the pre-established norms of the dominant culture:

...Personally, I believe, high school especially, it's a processing plant. You walk in there in grade 9, and you are about to be processed and in the end you will come out a product, for lack of a better word... the atmosphere lacks respect. It lacks principles, morals, [and] values. I think it invades everything about one's character, totally breaks it down to reconstruct another character (Dei 1997:146).

One can conclude that students' view the schooling process as one that denies the legitimacy of the Black experience (in addition to other groups) and operates as an assault on the personal/cultural attributes of ones character which leads to their underachievement or dropping out of high school (Dei 1997).

\subsection{LOW TEACHER EXPECTATIONS}

Daily interactions in schools between authority figures and students were another racialized barrier that was faced by many. Research has indicated that teachers have a huge impact on the way in which students perceive themselves as learners (Codjoe 2001:358). AfroCaribbean students attending Toronto high schools continuously spoke of teachers' expectations and attitudes as a detriment to their academic success. Some of the experiences that Black students noted include: differential/silent treatment from teachers, no encouragement, lower academic expectations and insensitivity.

Spence (1999) states "teacher expectations can be defined as inferences that teachers make about the future behaviour and academic achievement of their students based on what they know about the students [at the present time]" (p. 93). Research supports this view and has indicated that teachers identifying with the host culture retain "differential expectations" of students from different racial/ethnic groups and these "expectations" frequently shape programme offerings, teaching procedures and daily interactions in schools between student and 
teacher (Ross and Jackson 1991; Rubovitz and Maehr 1973; James 1990; Solomon 1996:218). Alternatively non-white teachers believe that they set high standards for students "from their own racial group" and provide an atmosphere conducive for them to learn and achieve to their fullest capabilities (Henry 1992; Ladson-Billings, 1992; Allen 1994; Solomon 1996:218).

Researchers have also identified two types of "teacher expectation effects" (Cooper and Good 1983; Spence 1999). The first "self-fulfilling prophecy effect," occurs when an initial "expectation" leads to actions that makes the "expectation" turn into something real; the second "sustaining expectation effect," takes place when teachers anticipate that their students will continue former "behaviour patterns" and neglect to make note of any improvements made in a student's abilities (Spence 1999:93). Generally, self-fulfilling prophecy effects are considered more dramatic than sustaining expectation effects since tremendous differences can be noted in a students' behaviour (Spence 1999). Meanwhile sustaining prophecy effects may take place even more often than usual because these occurrences are not as obvious (Good and Brophy 1987; Spence 1999).

Generally speaking to some degree all students have complained of perceived "problems" within the school system. Yet it is fairly clear that Black youth are having a rough time with present power structures in schools. Their concerns convey their disdain with the current education system as oppressive and to be blamed for the continued subordination they are confronted with. Many of the students' accounts revolved around issues of "power, authority, and respect" (Dei 1997:107). Black youth held the belief that authority figures must respect them in order to gain respect over them, therefore respect is something that is earned and not based on one's position relative to others. Students felt that many teachers were not generally concerned with the interest of students-only maintaining authority and discipline in schools as a result they were less cooperative with these individuals and felt they owed them no respect (Dei 1997:108). Teachers displayed their lack of respect through "insincerity, derogatory references, lack of interest, encouragement and support, and negative attitude" (Dei 1997:108). The following student accounts that appear below demonstrate some of the emotion and anger that has been created due to their negative interactions with teachers. The first is an explanation given by Eve who spoke of teachers' perceptions of Black students as athletes:

I don't think teachers really encourage us academically, but they do athletically. When they see you walking down the hall, they think you're a natural athlete. 
Take me, for example, I'm not a good basketball player, but every year the coach keeps asking me to come out for the team (Spence 1999:82).

Igor, a grade twelve student, stated the following with regards to his interactions with his coach:

My coach encourages me to do well academically, but that is just because he wants you to be eligible for the team. That way it brings a lot of attention to the school. You see it all the time. When you're finished, that's it-later. They don't care, they're just using us-so we have to look out for ourselves (Spence 1999:83).

Next, a grade eleven student named O.J. who was born in Canada spoke of the role he assumed to deal with his reality:

It was tough. I was at the back of the class chillin'. I was the class clown. I figured what the hell, they don't expect me to do well-at least that was my impression-so I didn't. When I did do well, they were always surprised. Some even thought I cheated (Spence 1999:83).

Finally, a grade eleven student, Steve expressed his feelings:

I don't think I really achieved the way I was capable of achieving. I don't know, I just wasn't into it. A lot of teachers just turn me off....Sure, they say you can get extra help, but they make you feel so stupid. I just stopped going (Spence 1999:83).

Similarly low expectations of Black students can be observed through comments made by teachers. In a study completed by Dei (1997) a teacher revealed that other teachers have mentioned that "they are uneasy about approaching a group of Black students [because] one "bad kid' [may be] in the bunch and teachers may tend to view and treat them as if they are all bad" (p. 111). Afro-Caribbean students are very familiar with the above occurrence and how teachers make implicit references to the way "they" behave and the way "they" hang out in the hallways of the school (Henry 1994:135). Therefore the above examples provide insight and demonstrate that educators view all Black students as being the same rather than as individuals (Henry 1994).

Whether educators are conscious or unconscious of the fact, they too exhibit differential expectations, which are race-based and affect their daily interactions with students (Henry 1994). For example, a teacher was reported to have said that Asians or East Indian students were regarded as potential mathematicians or scientists, unconsciously excluding the possibility that Black students may possess this potential (Henry 1994). Another teacher supposedly explained 
economic principles to an entire class and then repeated the lesson to a group of Black students to ensure that they understood (Henry 1994). A student made the following remark: "that could mean that he is a good teacher and wants to make sure that we understand; but it could also mean that he doesn't expect us to understand in the first place" (Henry 1994:135). These two examples are representative of the range of teacher expectations that Afro-Caribbean students come upon.

Students also recounted experiences of teachers belittling them by telling them that they should be in a lower academic stream or work at McDonald's which further contribute to the development of a negative self concept amongst Black youth. This occurrence is echoed through the following student's sentiments:

I really like to ask questions. That's how I learn ... [But the teacher], she'll manipulate the question in such a way that I answer my own question and then she says to me, 'You didn't really need to ask that question. I don't want you to ask questions if you don't need to.' And then I try to counteract by saying, "But I really didn't understand,' and she says, 'Well, if you don't understand maybe you shouldn't be in enriched math. Maybe you should ... take a course in plumbing.' She goes, 'You guys aren't very intelligent are you?' ... It's horrible. She should not be able to treat us like that (Dei 1997:129).

This type of condescending behaviour does not encourage students, in particular Black youth to pursue or excel in academics. It harbours feelings of inadequacy, failure, and alienation. Low teacher expectations only prove to legitimate the subordinate position that Black students occupy in the classroom.

\subsection{ALIENATING SCHOOL ENVIRONMENT}

In light of the racism, the harmful racial stereotypes, a disengaging curriculum that minimizes 'their' experiences/contributions, and teachers who expect less from them academically, Afro-Caribbean students must contend with another racialized barrier: the school environment, which many students described as "isolating" because there were a lack of role models (teachers, counsellors, administrators) in positions of authority that they could relate to. Some students, who had migrated from the Caribbean to Toronto, also alluded to this unfriendly and "seemingly hostile environment" as a contributing factor to their difficult adjustment period (Henry 1994). 
Black youth and parents strongly believe that student disengagement may stem from a lack of representation of Black role models in schools. Both parents and youth are in favour of schools hiring more Black and other minority teachers who would take on such roles as guidance counsellors, administrators, and support staff (Dei 1997). One can conclude that a representation of not only Black teachers is essential in helping students connect and identify with the school. Black and other minority teachers are able to offer alternative perspectives and life experiences that students would have never thought of or been exposed to because they also have to contend with the very same disadvantages as some of the students they teach. Therefore these individuals possess the ability to serve as role models for students that come from all walks of life. Allen also offers a useful analysis of how role modelling may work to enhance the schooling of these groups. She argues that (1994:190; Solomon 1996):

All teachers are role models. But not every teacher is a role model in every sense. They "model" their roles as teachers. They are what I call "ethical templates," men and women whose conduct sets standards for the exercise of responsibilities. Only some teachers are role models in the stronger, equally familiar senses I will label "symbols" of special achievement and "nurturers" of students' special needs (p. 218).

She reckons that the mere presence of role models (teachers of colour) can shatter misconceptions of who can teach but inspire one to believe that they possess the ability to excel above and beyond perceived expectations (Allen 1994:191; Solomon 1996). The following student response further conveys this message:

... if I saw a Black teacher in a classroom, I'd be proud. It's, like, it's someone that I can look up to, you know. I could identify with this person. This person knows what I have been through or he's ... already paved the road for me and if he can do it then I can do it (Dei 1997:173).

Closely related to the issue of role modelling Black students in Dei's (1997) study also indicated that they feel more at ease and better able to develop a strong rapport with teachers who had direct facts about the Black community and did not derive their knowledge from second-hand (and often biased) sources (p. 174). This is a very vital component in the learning process. When students are able to see themselves reflected in all facets of the education system learning becomes a much more pleasant experience.

There is a general sense of sorrow amongst Black students that is connected to the absence of Black teachers in schools (Dei 1997). Two students from Dei's (1997) study 
indicated that they felt the mere presence of a Black teacher in a predominantly White school would help minimize feelings of alienation. In the same way Afro-Caribbean students interviewed in Toronto secondary schools also mentioned some of the difficulties and barriers that they had encountered as a Black student being schooled by mainly White teachers. One student reflected upon his experience in the classroom:

With the White Teacher I am reluctant. I don't know why. Maybe I see some kind of barrier, whereas with the Black teacher, I can see that he is one of us. The barrier is imaginary, ummm ... just being in a White society (Henry 1994:134).

Another student offered this explanation for many of the problems confronted by AfroCaribbean students:

Some Black kids just come up from some other country and they don't know how to carry on with White teachers. They are only used to Black teachers back home where they are from, so it is kind of hard for them to cope with the White teacher. They probably say 'I'm scared to say things.' They just need some Black teachers so that they can look up to them and say, 'Hey, this guy is just like me and everyone is the same.' It takes you a bit of time to cope with the system (Henry 1994:134).

The above student accounts reveal the power and authority that one can possess which is determined by their race. Many Blacks and other racialized groups that have migrated to Canada view Whites as occupying a supreme position within the hierarchal structures of society. In addition they rarely interact with White people and when they do it is in positions of power and authority (various societal institutions). As a result of these perceptions some students may feel silenced and question their position and ability to interact let alone challenge a White teacher. Dropouts from Dei's (1997) study also indicated that the race of their teacher played a huge role in whether or not they took their schooling seriously. Some believed that Black teachers were not only more sympathetic but also more "demanding" and stern with Black students (Dei 1997). This mattered to dropouts because it demonstrated that a person in a position of power and authority was concerned about their well-being and therefore watched over them. Some students felt as well that the invisibility of Black counsellors in the school system functioned as a "deterrent" for Black students to willingly access counselling services (Dei 1997). This is due to the previously mentioned fact that White teachers are less able to sympathize with the realities of Black students, so this same assumption can be applied to White counsellors. Drastic changes need to be made in terms of the teaching body and support staff being representative of the 
student body, which would legitimate the demographic changes that have taken place in Canadian society at large. 

THEIR YOUTHS UNDERACHEVEMENT IN TORONTO HIGH SCHOOLS

Upon close examination of the formation of Portuguese and Afro-Caribbean communities in Toronto, it is clear the some experiences are parallel while others are not. Both communities were initially outlawed by immigration policy based on ethnic/racial characteristics, which prevented them from gaining entry and permanent settlement in Canada. Labour market trends also played a pivotal role in dictating when these groups were permitted entry into the country. For Portuguese immigrants, the main reason for their arrival in Canada was the demand of heavy manual labour during the 1950's, while for Afro-Caribbean people it was specifically the domestic scheme of the mid 1960's and eventually their middle levels of education. Early migrants from both communities also came to Canada, often times without their spouses or children and were separated over long periods of time. However, when the Portuguese are compared to Afro-Caribbean people it is clear that their earlier entry into the country was determined by their relationship to whiteness.

Even before Confederation there has been very early voyages though Portuguese migration to Canada was first documented in 1953, in the harbour of Halifax, Nova Scotia, with a ship called the "Saturnia" carrying Portuguese men who came as contract workers, (Marques \& Medeiros 1980). Soon after the arrival of these labourers, Canadian Immigration officials began to recruit Portuguese men, mainly from the rural areas of the Azores, to fill the demand for heavy manual labour in railway construction and agriculture (Marques \& Medeiros 1980). Almost all of these early migrants to Canada came without their spouses and children, and had to endure varied periods of separation, which lasted from two to five years (and in some cases up to ten years) (Nunes 2003:125). Eventually, most of these earlier groups of men soon left their rural employment and "migrated to cities to work in construction, cleaning, and manufacturing, where they set up the core of the first urban communities" (Nunes 2003:125). The mid 1970's marked the peak of Portuguese migration to Canada but this trend soon appeared to slow down to a few thousands in the late 1980's and early 1990's (Refer to Figures 1.1 and 1.2). This was in 
response to Canada's early Immigration laws of the 1970's which became increasingly rigid and emphasized sophisticated admission criteria based primarily on immigrant status, in addition to economic and humanitarian circumstances which were explicitly outlined; this meant that increasingly, rural Portuguese were admitted via the sponsored family class (Daniel 2005).

Since 1967 Canada's immigration policy is no longer explicitly discriminatory; race and ethnicity are no longer the primary determinant for gaining entry to the country. However, this process has been replaced by an assessment of one's education and skills as a measurement of one's ability to contribute to Canada's labour market (Anguiar 2006). As a result, Southern Europeans can be classified as an "in between" people because of what Anguiar calls the "biological eugenics" of previous immigration policy and the "social eugenics" of the point system's criteria for later selection of potential immigrants (Anguiar 2006). A more recent policy is clearly a social reproduction of earlier immigration law but is largely based on class, selecting middle - and upper-class immigrants who possess capital and entrepreneurial experience that can be utilized in Canadian businesses.

More importantly, by employing this practice of social eugenics within immigration policy, the government has been able to significantly curb access to the country through sponsorship and family reunification routes (Daniel 2005). Evidently Canadian officials chose these measures to control the "quality" of the types of immigrants that were migrating to Canada through the above paths, which was the case of most Southern Europeans, such as the Portuguese, who arrived in Canada through rapid chain migration during the early post war years. This pathway of migration to Canada was not regulated; it was left wide open and consisted of the sponsorship of distant relatives living in certain Southern European regions where strong kinship ties traditionally encompassed the extended family (Daniel 2005). The entry of these specific newcomers was of great concern to the government because they had poor levels of education and few job skills. In addition, the increased numbers of these groups settled in major cities such as Toronto in which they created self-contained ethnic communities that were unfavourable to the assimilation process (Daniel 2005).

The primary settlement of the Portuguese community occurred in the downtown core of the city of Toronto, mainly in Kensington Market and Alexandra Park (Teixeira 2000) (Refer to Appendix B). Poor working-class families noted the conditions of this area and resided in rundown housing, as the rent was far cheaper and they were close to friends, relatives, and other 
conveniences such as churches, stores, and employment. These neighbourhoods were previously home to other immigrant groups such as Jews, Italians, Poles, Ukrainians, and Hungarians (Teixeira 2000). As a result of its inexpensive yet capacious housing, these areas were attractive to immigrants and saw large ethnic turnovers in the $20^{\text {th }}$ century. Given the value placed on home ownership by the immigrant groups that moved there, however, most eventually bought their own homes and rented out space to the newest members of their community, who in turn saved and bought their own homes in the area.

Other than the value placed on home ownership, the Portuguese community displays a number of characteristics that reflect and perpetuate the subordinate position that their community occupies in Canadian society, and that have been passed on to their children, and the "gaze" they receive in the school system. Nearly $60 \%$ to $80 \%$ of the Portuguese who have settled in Canada come from Azorean origin (Nunes 2003). This specific community has been marked with remarkably low levels of education, which has been attributed to Portugal mandating significantly lower minimal educational levels than those of other European nations during the 1940's 50's and 60's (Nunes 2003). As a result of this measure, the average educational attainment for first-generation Portuguese migrants who arrived in Canada from "1953 to 1973 was only four years of primary schooling, a figure which was lower than the norm for other immigrants to Canada" (Nunes 2003:126). Currently, "the Portuguese-Canadian community has the lowest education of any ethno racial minority, behind only those of the Aboriginals, Inuit and Metis (the descendants of early French settlers and natives)" (Census 1996 data cited in Nunes 2003:127). Also, a recent study done in Toronto pointed out that a specific segment of Portuguese-Canadians who ranged from the ages of 20 to 64 had the lowest levels of university-educated individuals and the highest proportions of individuals obtaining only primary schooling (Nunes 2003). The above information paints a graphic illustration of the severe educational disadvantage of many Portuguese families living in Canada, which has also replicated itself in the second and third generations of the community. It is this later fact, however, that this chapter explores.

A resulting common characteristic of the Portuguese community is that they are overwhelmingly concentrated in blue-collar occupations. For instance, in "Toronto PortugueseCanadians are excessively concentrated in unskilled and manufacturing jobs, and underrepresented in skilled, professional and management positions (even when compared to 
other immigrants)" (Nunes 2003:128). A study conducted on ethno-cultural inequality in Toronto indicated that Portuguese-Canadian men and women were the only group of European ancestry that could be found working disproportionately in unskilled blue-collar occupations in comparison to 20 recent visible-minority groups (Nunes 2003). However, despite these facts it is quite interesting to note that many Portuguese living in Canada have avoided being disproportionately represented among the poor (Nunes 2003). This can be attributed to the hard work ethic that exists in working class Portuguese homes as well as to the number of income earners who live in a household and are expected to contribute to the family expenses. As noted above, the majority of Portuguese citizens view homeownership as a secure economic investment, as well as a symbol of their success in Canada (Teixeira 2000).

Nevertheless, the fact that Portuguese immigrants are, as mentioned, over represented in terms of blue-collar occupations, and amongst those facing low educational levels has resulted in a lack of leadership within Canadian society. In other words, the Portuguese are underrepresented in all realms of society, including political, economic, social, and cultural institutions, despite the fact that they have been here for over 50 years. Also adding to this phenomenon is the fact that Portuguese youth are not recognized as a designated group under the Federal governments Employment Equity Act (1995), which has been used as "the basis for most equality of opportunity programmes in education, culture, and employment" (Nunes 2003). To the extent that Portuguese youth do not qualify themselves by education for higher-level positions, employment equity measures cannot help them, as they are not being disqualified from better opportunities by virtue of the discrimination of others; rather it is their own lack of qualifications that keep them in working class occupations. To some extent, therefore, the Portuguese community has internalized their subordinate position within mainstream society as inevitable, even though their marginalization has been precisely constructed and orchestrated by the original immigration policies that brought them here to fill specific labour market requirements in this country, and unfortunately they continue to hold these dead-end, although not always low-paying, occupations at the moment.

\subsection{The CAUSES OF PORTUGUese Youths UNDERACHIEVEMENT IN TORONTO HiGH SCHOOLS}

Upon closer examination of the academic underachievement of Portuguese students a number of recurring issues may possibly be at the source of the disproportionate dropout rates 
observed amongst youth from this community. Cheng, Yau and Ziegler (1993) found in their study on secondary students from the TDSB that Portuguese youth spent a reported 18 hours doing part time work, which were the longest average hours when compared to the overall student population (p. 31). A direct result from their part-time employment is that Portuguese students reported spending the least number of hours ( 7 hours) to complete homework when compared to the overall ( 10 hours) student population and were less likely ( 25 percent) to be involved in extra-curricular activities than most other students in Toronto secondary schools (Cheng, Yau \& Ziegler 1993:18, 36, 38). In a 1997 study research findings also indicated that Portuguese students still continue to spend far more time doing part-time work ( 16 hours) versus the average number of hours (12 hours) a week reported by the general student population (Cheng \& Yau 1999:24).

This noted tendency can be directly related to the fact that some parents have focused on their "economic progress" in the country instead of being actively involved in their children's education (Nunes 2003). As a result some Portuguese children have been encouraged to obtain employment "prematurely" as a means to assist with the purchase of a home (Nunes 2003). The majority of Portuguese immigrants (more than 90 percent) were cited by Teixeira (2000) to still view homeownership as an experience that "brings a feeling of having succeeded in this country (Canada) and [an] accomplishment of a dream" (p. 214). The following matter can be further conveyed through the sentiments of Brum, a counsellor from the TDSB who stated: "this is our struggle; we still have some who value buying a home and a car more than getting a postsecondary education" (Brown 2006:1). Another person who resides in Toronto also had a similar comment "there are many people who are not interested in their children going to school. They would rather see their children come through the door with $\$ 100$ or $\$ 200$ a week..." (Nunes 1998:27). Therefore some parents have chosen to concentrate all their efforts on purchasing a house which intern becomes a "family project" that they become bound to due to the lack of fluency in English which has hindered their participation in the life of mainstream Canadian society (Nunes 2003). As a result of their focus on home ownership over higher education some Portuguese community leaders have speculated that as a culture they may have made it fairly easy for weak students (particularly boys) to leave school early in pursuit of obtaining employment on a construction cite making a fair amount of money ( $\$ 25$ to $\$ 30$ per hour) (Brown 2006:2). Through this practice many parents have actually contributed to further 
alienating themselves and even more so their children because some parents have failed to appropriately integrate themselves into society, which has led to their children's inability to effectively negotiate the middle class school system. The tendency for Portuguese youth to plan for full-time employment is also evident from data obtained by the TDSB. In the 1991 study 10 percent of Portuguese students intend to be employed at a full-time job once they have graduated from secondary school (Cheng, Yau \& Ziegler 1993:33). In a later study a noticeable increase was also observed amongst Portuguese students whereby 17 percent stated that their intentions were to be employed upon graduating high school (Cheng \& Yau 1999:32). This is further illustrated through the following comment: "...Everyone is too worried about... buying a car... ... a full-time job... ... So no one really thinks about school" (Nunes 1998:26). Evidently the hard work ethic of many Portuguese parents pursuit to own a home has incidentally marginalized their children from achieving their full academic potential. This has led to subsequent generations following in their parents, footsteps by obtaining employment in blue-collar occupations since they do not possess the educational credentials that would qualify them for work in professional careers.

Next, another factor that has greatly contributed to the many difficulties that Portuguese youth are faced with in the school system is that their parents have been reported to comprise the highest proportion ( 47 percent) of individuals who had acquired as far as elementary school education (Cheng \& Yau 1999:12). This finding can be attributed to the initial wave of Portuguese migrants that arrived in Canada from one of the few countries that had mandated secondary school education as optional throughout most of the $20^{\text {th }}$ century (Brown 2006:2). As a result of their low levels of educational attainment the parents of Portuguese students tend to maintain their low socio-economic status and are found concentrated in skilled or semi-skilled fields of employment (Cheng, Yau \& Ziegler 1993:36). The following statement made by professor Nunes (vice-president of the Portuguese-Canadian National Congress) reaffirms the position that many Portuguese families hold in Canada "we're still a massively working class community and a lot of parents don't know where to go for help for their children, between the education barriers and the language barrier and shift work"(Brown 2006:3). Similarly Santos, a mother stated the following "I'm not putting down Portuguese - "I'm Portuguese my self — but a lot of our parents had the language barrier when we were growing up and they didn't really understand education was important" (Brown 2006:3). 
The above example is also conveyed through a study completed by Cheng and Yau (1999) who found that Portuguese students were reported to receive very little assistance with homework from their parents, which ranged from 11-15 percent in comparison to 27 percent of the general population (p. 27). The low educational levels of many first generation parents in addition to their limited fluency in the English language has clearly operated as a deficit in helping their children with schoolwork and for some understanding the value of education. Nunes research findings have also noted some of the reasons behind the lack of proficiency in English amongst first generation Portuguese parents. The respondents from Nunes (1998) focus groups "lamented" that many individuals have not learned to speak English "out of sheer complacency" in addition to a number of other factors which included the urgency for immigrants to obtain employment to ensure some security in the country, the shortage of "accessible child-care," parents reliance on children to act as interpreters (resulted in no need to learn English), and the fact the some E.S.L. programmes (Language Instruction for Newcomers to Canada-LINC) are not made available to Canadian citizens therefore members from the Portuguese community are unable to access such programmes (p. 29). Currently, the objective of the LINC programme is "to facilitate the social, cultural, and economic integration of immigrants and refugees into the [country]" by offering classes that will familiarize newcomers with the heritage and culture of Canada as well as the use of technology to prepare clients for job searches and interviews (Citizenship \& Immigration Canada 2004:1). This programme has also developed linkages with schools that have high immigrant populations by providing interpreters and settlement workers to facilitate effective communication between students, parents, and teachers. It is worth noting that such programmes as LINC were not available until recent years (1992) therefore many immigrants from the first wave of Portuguese migration were unable to access these services, which would have greatly benefited countless parents and their children.

As a result of their parents working class status and some of the barriers that youth have faced in the school system the Portuguese community still "remain[s] the least likely new Canadians to go to college or university" despite their presence in the country for over fifty years (See Figure 1.3)(Brown 2006:2). A study completed by York University professor Michael Ornstein indicated that approximately 12 percent of Toronto's Portuguese community have presently attained a university degree, which is a remarkable change from the 1 percent, reported in 1971(Brown 2006:2). Although research from the TDSB illustrates a startling finding, 31 
percent of Portuguese students were documented as the highest proportion of learners that were unsure of their post-secondary plans (Cheng, Yau \& Ziegler 1993:33). A follow up study completed in 1997 Portuguese students comprised the second highest group of students that were undecided about their plans to pursue post-secondary education ( 24 percent) and were amongst the second lowest percentage of students who intended to go to university (29 percent) (Cheng \& Yau: 1999). Some believe that this uncertainty may be rooted in traditional rural Portuguese society whereby parents formed "definitions of personal identity" in opposition to the cultural patterns of those individuals occupying influential positions in the political and economic spheres of society (Nunes 2003:147). Therefore from the perspective of some youth in the community, obtaining post-secondary education may be equated as an effort to gain entry into the exact roles that, parents and friends have been opposed to by means of tradition (Nunes 2003:148).

In the same way Portuguese-Canadian youth have formulated their identity based on the above principles, however it is based upon social class and ethnic features (Nunes 2003). Since the majority of youth from the community have not witnessed their parents working in whitecollar occupations, then gaining employment in a professional career would signify to many Portuguese youth that they have assimilated "into a mainstream Canadian identity" (Nunes 2003:148). Closely related to this concept of assimilation is an experience described by Nunes (2003) who explains that a close friend once made a humorous remark to him by stating: "You can't go to University! You're Portuguese! Don't you know that Portuguese are not supposed to go to University?!" (Nunes 1999:1; Nunes 2003:148). Therefore some youth view admission into university as a symbol of leaving their families social class behind and "their sense of being Portuguese" which many believe is an attempt by the school system to socialize students in accordance with the norms of mainstream culture in an effort to "annihilate" the identity of "Portuguese-Canadian" youth (MacLearn 1996; Nunes 2003).

Equally important to note is the fact that Portuguese youth "stood out" as a collective of students that had limited "access" to computers at home and irregular use of computers during school (Cheng \& Yau 1999:28). The same study compiled by Cheng and Yau (1999) also revealed that a considerable amount of lower income groups made effective use (i.e. "writing, finding information, producing graphs, and doing math") of school computers on a "daily or weekly basis" in comparison to higher income groups ( $p .20)$. This particular phenomenon 


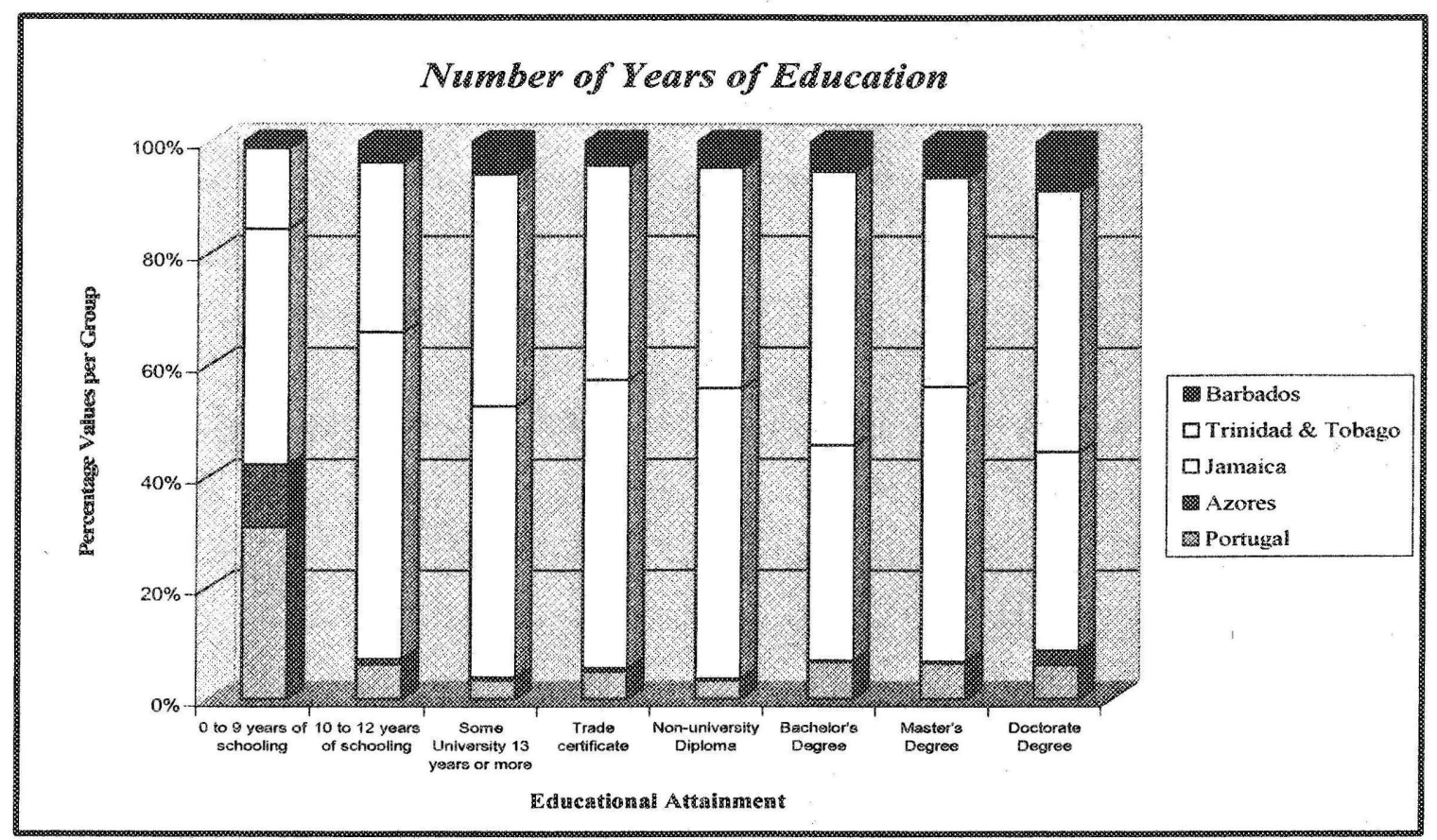

Data Source: Landed Immigrant Data System

amongst Portuguese youth may in fact be attributed to the above traditional belief system that some youth have developed through observing their parents behaviour patterns. Since technology is widely used by mainstream society some Portuguese students may also view the use of these devices as part of the assimilation process. It is quite evident that members of the Portuguese community are deeply entrenched in these traditional cultural values that have been ingrained in the minds of many individuals, which are passed onto subsequent generations that still hold these beliefs despite being raised in Canada. However this trend is extremely disturbing since the economy is constantly changing and "more than 70 percent of new jobs in Canada are predicted to need some post-secondary education (Brown 2006:2) For this reason it is imperative that Portuguese-Canadians break the blue-collar cycle or future generations will be faced with dismal employment opportunities. 



\section{YOUTH IN TORONTO HIGH SCHOOLS}

When the academic performances of Portuguese and Afro-Caribbean students are compared there are some notable similarities and differences that are apparent. Both communities have demonstrated similar statistical performance in schools, which has led to the acute drop out rates reported in Toronto high schools. In addition the school curriculum and low teacher expectations have also operated as a barrier for Portuguese and Afro-Caribbean students to achieve success. Both communities also share the same class position, which can be viewed as a potential bridge in understanding the similarities in their academic underachievement. On the other hand however racism has played a significant role in dictating the experiences of AfroCaribbean students in the school system while Portuguese students are met with educational inequalities that challenges their schooling experience. The above noted differences will be examined in terms of these three barriers Racialization (Anti-Black Racism)/Non-Racialization, negative (racial) stereotyping, and (alienating) school environment, which have all contributed to some degree or another in these students disengagement from school.

The Toronto District School Board (TDSB) has produced a number of Commission reports that have monitored the progress of ethno-cultural and racial minorities since the 1970's (Nunes 2003). The studies revealed that students from both the Black and Portuguese communities continue to be over-represented in leaving school early or disproportionately found amongst those students designated "at-risk" of dropping out and have some of the lowest graduation rates of some of the groups sampled (Royal Commission 1994). Data collected by the Toronto Board from the 1991-92 period indicates that Whites comprise 54 percent of students that completed surveys while Blacks comprise 9 percent of the survey sample (Cheng, Yau \& Ziegler 1993:16). These numbers can also be broken down by language and ethnicity as well as by place of birth however since the focus of this project is on youth from the Portuguese and Black communities only these groups of students will be identified. Evidently, Portuguese students account for 17 percent of the "White" survey sample. Of those surveyed 62 percent of 
Portuguese students are Canadian-born and more than half of these youth, 56 percent have arrived in the country since 1987 (See Figure 1.4) (Cheng, Yau \& Ziegler 1993:20). Whereas Black students were further divided into three major groups according to their country of birth: Canada 31 percent, the Caribbean 34 percent (See Figure 1.4), and Africa 24 percent (Cheng, Yau \& Ziegler 1993:16). Given that the focus of the current project is on the underachievement of Afro-Caribbean youth the first two groups of Black students will be used. Since Blacks from the Caribbean (mainly Jamaica, Trinidad/Tobago, Guyana and Grenada) began to migrate to Canada during the mid 1960's therefore second-generation youth (born in Canada) may be amongst the survey sample of students that indicated Canada was their country of birth (Cheng, Yau \& Ziegler 1993). A research finding from the TDSB also supports this observation and is closely related to Afro-Caribbean immigrants migrating to Canada earlier than their African counterparts, which has resulted in the percent of immigrant arrivals from the Caribbean to decrease from 42 percent to 16 percent between 1987 and 1991(Cheng, Yau \& Ziegler 1993:20). This drastic change was marked by an increase in the percent of foreign-born Black students that arrived from Ethiopia and Somalia, which rose from 39 percent to 50 percent as of 1987 (Cheng, Yau \& Ziegler 1993:20,37).

Figsre 1.4 Country of Bird by Age, 1980-2000.

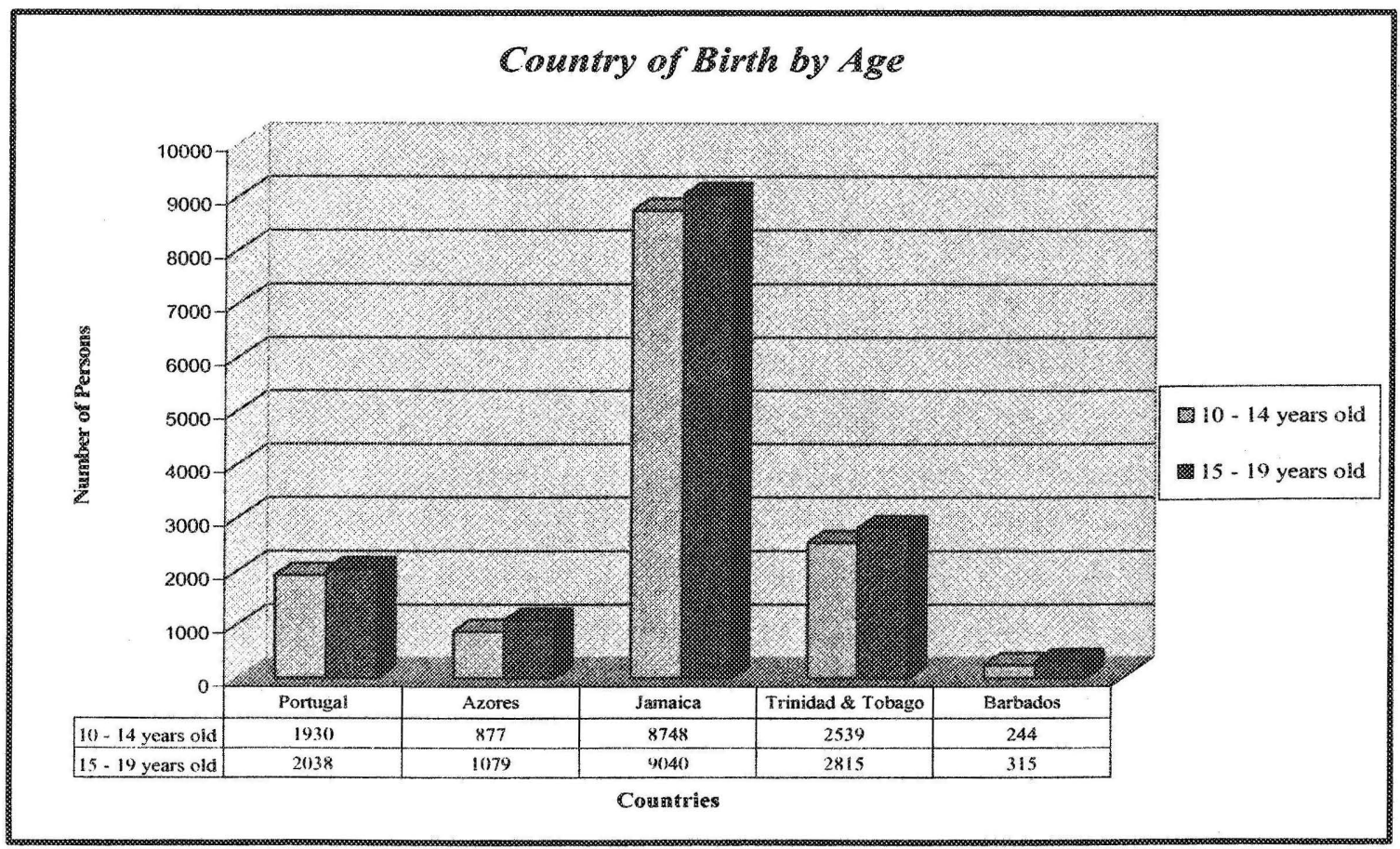

Data Source: Landed Immigrant Data System 
The academic underachievement of both Afro-Caribbean and Portuguese students in Toronto high schools is very disturbing. Consequently, youth who leave high school without obtaining their Ontario Secondary School Diploma (OSSD) experience some difficulty in the transition process from school to work because they lack the skills and confidence to be successful in their adult lives (Kilbride \& Anisef 2001:20). Youth from both communities have demonstrated disproportionate failure rates and are most likely to be labelled "at-risk" and leave high school prematurely. This section of the chapter will outline specific elements that exist in the education system that have contributed to the similarities in poor academic performance observed amongst Afro-Caribbean and Portuguese youth. Statistical data from the TDSB and the following two barriers (developed in Chapter 2 to discuss the experiences of Afro-Caribbean students) biased curriculum/texts and low teacher expectations will be used to demonstrate that youth belonging to both communities encounter these common challenges through the schooling process.

\subsection{STATISTICAL PERFORMANCE}

Data gathered by the TDSB from the 1991-92 period indicated that Black and Portuguese students shared many similarities in statistical performance. According to research data 36 percent of black secondary school students were "at-risk" based on their grades reported in English and Math courses. This trend was also replicated amongst Black students in advanced level courses and when the "Black student category" was sorted by youth born in Canada, the Caribbean, and in Africa (Royal Commission 1994). Similarly 33 percent of Portuguese students were "at-risk" which was indicated by their low grades and the slow pace at which course credits were being accumulated (Royal Commission 1994). In a subsequent analysis, the Toronto Board tracked students in Grade 9 in 1987 from the same groups and examined how successful they were in graduating from secondary school. The study revealed that 42 percent of the black Grade 9 students had left school by the end of 1992 without graduating (Royal Commission 1994). Meanwhile a similar tendency was revealed for Portuguese students, 41 percent had left school without graduating (Royal Commission 1994). Even after considering the family's socio-economic status, the pattern remained unchanged when comparing children of semi-professional parents; Portuguese youth were still at a greater risk of dropping out than other students (Royal Commission 1994). Likewise the tendency to drop out could even be observed 
amongst black students whose parents were university educated, employed in professional occupations or who lived with both parents (Royal Commission 1994). With regards to the Portuguese-speaking, those students born in Canada versus those born out-side the country had slightly higher levels of achievement (Royal Commission 1994). Unfortunately for this analysis, there is a lack of differentiation between Portuguese-speaking students from the mainland and those from the Azores (Royal Commission 1994). Although migration patterns have indicated that the majority of Portuguese $(60 \%$ to $80 \%)$ came from the Azores and settled in Ontario (Nunes 2003:126). This is a very significant finding since many studies have identified differences in educational levels between those from the mainland and those who are from the Azores who tend to have lower education levels and are very conscious of their limitations compared to those from the European mainland (Nunes 1998:35).

\subsection{BIASED CURRICULUM/TEXTS}

Next, parents from both the Black and Portuguese communities have expressed their disdain with the current curriculum/texts because it does not reflect the cultural experiences and contributions of their specific communities. Afro Caribbean parents have stated that the curriculum tends to be racially biased because it only propagates Eurocentric standards and does not reflect the diverse cultures and experiences of students in the classroom. Similarly, Portuguese parents believe the curriculum should acknowledge their language and cultural heritage, but although these parallels do exist in curriculum it is worth noting that the cultural non-acknowledgement of Portuguese heritage should not be confused with the racialized exclusion of the contributions that Blacks have made in Canada. Black and Portuguese history/heritage months are suppose to combat these gaps in curriculum. However some would argue - particularly Black parents - that it is only being used as a "museum" culture. In the case of the Portuguese community, in 2001 Canada declared June a heritage month, with June $10^{\text {th }}$ being Portugal Day. Yet it has not received much media coverage or promotion, which results in mainstream society's continual ignorance of the contributions made by the Portuguese community to this country. For these reasons this particular barrier is incredibly destructive to students that are unable to identify with dominant cultural standards since the current curriculum is used as a means to assimilate students to become Canadians in the "truest" sense. This process of acculturation requires the student to give up a part of their identity, which defines who they 
are (by culture or language and in some cases both) to adopt the cultural traits or social patterns of the dominant group. In the previous section educators referenced the dominant group as the founding groups of Canada Britain and France to which our education system has been built on and therefore only their contributions are significant since the minority presence is only fairly recent. As a result of this barrier students are in constant conflict with themselves and parents who may hold strong traditional values of their culture and see their children as abandoning their identity to adopt Canadian cultural standards.

In a study conducted by Cheng and Yau (1999) students were asked to indicate whether they learned about the achievements, contributions and experiences of different racial/cultural/religious groups (p. 38). Afro-Caribbean students stated 77 percent while Portuguese students stated 79 percent the responses ranged from "all the time," "often," or "sometimes" (Cheng \& Yau 1999:38). Despite the high numbers shown above it should be noted that these numbers were obtained by combining the three different responses. There is a great difference between students who indicate learning about something "all the time" versus "sometimes." Further investigation is needed into which racial/cultural/religious groups were selected for study, and how the selection process worked. These are all vital questions since they determine whether the authentic experiences of all students are being reflected in the curriculum. However this is questionable since the dropout rates for both the Afro-Caribbean and Portuguese communities still remains very high in comparison to the provincial rate. Another interesting detail noted in Cheng and Yau (1999) research findings is that close to half of secondary school students stated that they had learned in class how to detect biases and stereotypes in learning materials (p. 17). Upon further examination of this detail it was revealed that many of these students were enrolled in the academic stream taking Social Sciences courses and Language/Arts which offers more exposure to the above noted items than those students who chose to specialize in math, sciences and technology or were in the general programme (Cheng \& Yau 1999:17-18). This is a significant finding since the majority of Afro-Caribbean and Portuguese youth are saturated in general or basic level courses as a result they are not learning these concepts, which are instrumental in them making sense of their lived experiences.

Many of the concerns that have been expressed with regards to this barrier and Black youth have also affected Portuguese students. Nunes (2003) states, "for nearly four decades, Portuguese-Canadian students have consistently ranked amongst the groups with the most acute 
educational problems" (p. 131). Also a report that dates back to the first half of the 1960's on immigrant adaptation and the social services, described how recent arrivals from the Portuguese and Italian communities were about to be confronted with a grave dropout problem (Ferguson 1964; Nunes 2003:133). Subsequent reports and studies from this period to the present moment have continued to reflect the above trend that Portuguese students have the lowest graduation rates in comparison to other groups (Nunes 2003). In response to the above crisis the Portuguese-Canadian Coalition for Better Education was formed in February of 1995 in response to the statistics that appeared at the beginning of this section from the 1991 Every Secondary Student Survey (Nunes 2003). It is worth noting that not until the late 1990's was the Coalition aware of the Portuguese communities dismay with the current education issue (Nunes 2003). Parents would like the existing curriculum to better reflect the presence and contributions of Portuguese-speaking people to Canada in the classroom since the current system perceives it to be a "heritage" rather than a practical international language (Royal Commission 1994). Therefore both the Afro-Caribbean and Portuguese communities are equally concerned that their children's underachievement stems from the degree to which their children can identify and connect the current curriculum to their immediate position. Parents of both communities would like the existing curriculum to acknowledge the presence and contributions that racial and ethno cultural groups have made towards Canada, which would then foster an enduring sense of "cultural pride" amongst these students and legitimize their status as "Canadians" in the classroom as well as society at large.

\subsection{LOW TEACHER EXPECTATIONS}

Finally low teacher expectations have also contributed significantly in youth from both communities leaving school prematurely or obtaining full-time employment in dead end jobs once they have graduated from high school. These practices are not a part of the formal curriculum but get transferred through the everyday practices, attitudes, and expectations of those who are in a position of power and authority such as teachers, counsellors, and administrators (Henry 1994). The following data cited in Cheng, Yau and Ziegler (1993) study reinforces the message that students unable to effectively negotiate the standards of the "middle" class education system are more likely to disengage form the schooling process and seek alternative paths such as 10 percent of Afro-Caribbean students who are more likely to plan for 
full-time work after high school versus the overall 5 percent of the student population (p. 33). Likewise the above trend was also observed amongst Portuguese students unchanged at 10 percent (Cheng, Yau \& Ziegler 1993:33). In a later study conducted by Cheng and Yau (1999) 14 percent of Afro-Caribbean students indicated yet again (with significant numbers) their plans to obtain full-time work immediately after high school (p. 32). Although in the above study a slightly higher trend was observed amongst Portuguese students at 17 percent (Cheng \& Yau 1999:32). This closely coincides with complaints made by Portuguese parents that teachers have low expectations of their children and young adults, which was conveyed at a meeting (The Royal Commission 1994). For example, Fernandes, a PhD literature student also had this to say with regards to teachers' behaviours further perpetuating low standards for Portuguese students: "I hear that a lot 'Oh, he's a Portuguese student; what can you expect?' or "He's Portuguese? Better give him just five pages to read instead of 10" (Brown 2006:2). In the same way a Portuguese student from Toronto had this to say:

They labelled me as a basic student, so the teachers kind of tried to push me towards lower education, but... ...I have the will and I got grade 13 math and grade 13 English. Now, I'm... not a good speaker ...I'd go home every time and complain to my parents. My parents would say... 'stick with it, just think of it... ...the more education you have, the better it's going to be for you', so I kept going, going, going... Every day, at home, we'd have a fight or something about... school, or whatever. I take it out on them ......I'm suppose to take it out on the teachers, but... I just try to do the best I can (Nunes 1998:32).

Clearly, their frustration stems from these everyday struggles that students (from racial/ethno cultural groups) are faced with that eventually lead to these youth giving up because of all the "extra" hurdles they are confronted with in the school system. This has resulted in a considerable proportion of students from both the Portuguese and Afro-Caribbean communities who have chosen to locate full time employment to compensate for some of the "inappropriate" judgements that have been passed by teachers or guidance counsellors about their academic performances in class.

However, in a subsequent study generally students that have chosen a specific occupation are moderately higher among Blacks (35 percent) in comparison to other racialized groups (2428 percent) (Cheng, Yau \& Ziegler 1993:34). Although it is worth noting that Blacks from the Caribbean (40\%) were among one of the groups to show the highest percentages of a specific career in mind (Cheng, Yau \& Ziegler 1993:34). A later study completed by Cheng and Yau 
(1999) further supports the above claim that Black students have specific aspirations to pursue careers in teaching or law, which were noted amongst Canadian born Blacks who demonstrated slightly more confidence in their communication skills than students born in the Caribbean (Cheng \& Yau 1999:33). In the same study it was also confirmed that a strong proportion of students have intended to register in community college or obtain full-time employment immediately after high school. Portuguese among other (i.e. Tamil, Filipino, Aboriginal, and Foreign born-Blacks) students were more inclined to "hold positions as waiters/waitresses, labourers, couriers, and factory workers" (Cheng \& Yau 1999:25).

Clearly the choices that Afro-Caribbean and Portuguese students have made with regards to their career options or aspirations have mainly been impacted by the way in which they are perceived in the school system by authority figures and where they have been placed (academic streams) to materialize these dreams. Although the Portuguese experience is somewhat different from Afro-Caribbean students in terms of other factors that are at work and include family and cultural obligations (these were discussed at great lengths in Chapter 4). It is interesting to note that despite the fact that these youth have been placed in general or basic streams some still remain optimistic and committed to pursue their ideal career goal. For some this is possible but others will soon come to the realization that it is impossible to get into university when you have solely taken applied or workplace destination courses. As a result many Afro-Caribbean and Portuguese youth will be forced to find employment and work full time. Although the numbers above indicate that many are planning to work immediately after school, it would be essential to know if full-time work is being obtained to save money in order to attend college/university in the following year. This particular detail is crucial in determining who is actually intending to make a permanent transition from school to the workforce.

\subsection{RACIALIZATION-ANTI-BLACK RACISM}

In contrast to the previously mentioned educational inequalities that have contributed to the poor academic performance amongst Portuguese and Black students alike is only one aspect of this problem. Through further investigation of this issue one can conclude that anti-black racism has played a pivotal role in the position that Black students occupy in the school system and Canadian society at large. Undeniably the specific character of racism that Afro-Caribbean youth have had to tackle in the education system have contributed significantly to their poor 
performance in Toronto high schools and have led some students to develop a disinterest in education as a means to achieve success in life. These differences will be examined by using the following barriers anti-black racism, negative racial stereotyping, and alienating school environment, in addition to data from the TDSB and current research to demonstrate how racism has manifested itself in the daily practices of the schools. Also in an attempt to gain further insights regarding the underachievement of Portuguese youth in Toronto high schools the above barriers will be contrasted with the realities of Afro-Caribbean students to critically evaluate this issue. Since Portuguese youth are not from a racialized group the above barriers will be examined and contextualized by reviewing some of the predisposing and causal factors that have contributed to their acute dropout rates.

Unlike their Portuguese counterparts Afro-Caribbean students have been affected adversely by the institutional racism that is present in the secondary school system that assesses and streams students into classes that lead to workplace, college and university destinations. Data obtained from the Toronto Board in the $1991-92$ period indicated that the 9 percent of secondary school students who were black made up 16 and 18 percent of the General and Basic level classes (Royal Commission 1994). The above information is a grave manifestation of antiBlack racism, which may in fact operate parallel to negative racial stereotyping whereby superficial beliefs are used to assess, discipline and place students in various learning streams. Often times, these decisions disadvantage Black youth (or other racialized groups) and further contribute to their marginalization in Canadian society. Upon examination of data provided by the Royal Commission the practice of Anti-Black racism is quite evident and actively used to determine the placement of Afro-Caribbean students. When the Royal Commission (1994) did an analysis of racial groups and used place of birth as part of their assessment,

Canadian born Black students of Caribbean descent are over-represented in basic and general-level math course, but equitably represented in the various English course levels. [Meanwhile] foreign-born Black students of Caribbean descent are over-represented in basic- and general-level English and math programs... (p. 7).

This finding is a very disturbing reality that the majority of Afro-Caribbean students have had to encounter. Previous references have indicated that these systemic forms of racism can prove to be especially detrimental for youth belonging to racialized groups since individuals (i.e. teachers and administrators) that work in institutions such as the education system possess the power and authority to shape their future. Similarly a mere 44 percent of Black students were 
enrolled in advanced math, in comparison to a considerably greater proportion of other students (Royal Commission 1994). By and large the proportion of Black students being placed in general and basic level courses limits their future opportunities to gain entrance to postsecondary education programmes as well as diminishes one's self esteem to pursue their dreams and aspirations. Consequently, these practices further increase the risk of Black youth dropping out and can be reinforced by TDSB data "which indicates the dropout rate for all students was: 21 percent from the advanced level, 48 percent from the general and 64 percent from the basic" (Royal Commission 1994:7). These numbers are devastating and it would be interesting to know how many of these youth encountered punishments from schools (such as suspensions or expulsions) that would have impacted more heavily on racialized students in basic/special needs classes (Ontario Human Rights Commission 2004:7). Often times why many students make the ultimate decision to leave school is because when they return they experience difficulty catching up on missed work since they were unable to access alternative education services (Ontario Human Rights 2004). All of the above references demonstrate how schools shift and place AfroCaribbean youth in lower academic streams based on their race or country of birth. It is quite evident that these forms of assessment are based on subjective evaluations that are racially biased against Black youth that are born either in Canada or the Caribbean.

\subsection{NEGATIVE RACIAL STEREOTYPING}

Next, the effects of this particular barrier negative racial stereotyping are overwhelming and have led to what some Black parents view as a "crisis" in education concerning their children. The everyday practices of authority figures determine the destinations of future students in society. Therefore if students are streamed into particular courses in large numbers (for example into vocational courses), it becomes acceptable to see them there. As a result these students are not being judged based on their natural abilities but by the perceptions of staff who act as "gatekeepers" to their future. Many parents from the Afro-Caribbean community and some (but not all) from the Portuguese community perceive the underachievement of their children as a disaster, since their children are being streamed into basic and general level courses, which limit their opportunities to enter post secondary institutions. Studies of Black youth living in the Metropolitan Toronto area reveal "that during the seventies and eighties most believed that education was important to their success in this society and racism and 
discrimination were merely 'obstacles' that they would be able to overcome through their high level of education" (James \& Brathwaite 1996:21). James (1990:113; 1996) also explains that aside from youth equipping themselves with education they believed that all obstacles could be overcome by adopting an approach that would prove they are:

... Hard working, being determined, relying on their own abilities and skills, having the 'right' attitude, high career aspirations, a conviction that nothing will stop them, and the aspiration to become 'the best,' since it is only by being the best that they will be able to counter the obstacles (p. 21).

Therefore Black students unable to successfully "negotiate" the "White" middle class education system viewed racism and discrimination as hopeless impediments to their educational success and therefore withdrew from school because they believed education offered very little opportunity to succeed in society (James \& Brathwaite 1996).

The situation described above was the reality of Afro-Caribbean youth in the school system during the "1970's and 80s [that closely parallels] Blacks in Britain, most of whom share similar backgrounds in terms of being second generation Caribbean immigrants to Britain" (James \& Brathwaite 1996:21). Evidently many Black Caribbean youth in Toronto high schools still continue in their struggle to negotiate their position in a school system that does not value their culture or even their presence in classrooms. This barrier has led to some Black youth viewing extra-curricular activities as an escape or tool to be used to obtain "super star" status and success. Overall 27 percent of Blacks are involved in extra-curricular activities (Cheng, Yau \& Ziegler 1993). However, upon further investigation Black students bom in Canada (33 percent) and the Caribbean ( 31 percent) take part in most extra-curricular activities (Cheng, Yau \& Ziegler 1993:28). This finding coincides with the many student accounts that allude to the fact that Blacks (in particular males) are more likely to be encouraged to participate in sports rather than pursue academics. It would be quite interesting to know the gender ratios for the above data to see if there is a huge difference between male and female participation. Also a follow up study by Cheng and Yau (1999) confirms that Afro-Caribbean youth continue to be immensely encouraged to participate in extra-curricular activities (63 percent) at school ( $p .40)$. In addition, the research indicated that Afro-Caribbean students are given 34 percent of their awards in sports (p. 40). Overwhelmingly the data reaffirms that negative racial stereotyping is active and being practiced in Toronto high schools. It is apparent that media stereotypes of Blacks as athletes are 
further perpetuated in schools as a more viable and acceptable avenue of career choice for AfroCaribbean youth.

Subsequently an additional consequence of this barrier has resulted in Blacks being less likely than most other students to plan for university, but more likely to aspire for community college. This is especially true for Caribbean-born Blacks. The percent of Caribbean born Blacks with university and college plans are 29 percent and 38 percent respectively versus 56 percent and 17 percent for overall populations (Cheng, Yau and Ziegler 1993:37). This data echo's the sentiments of many Black parents disdain with their children's lack of interest to pursue post-secondary education.

Equally important and quite a tragic aspect of this barrier are the repercussions of the "Safe Schools Act" or "Zero Tolerance" policies called Bill 81 that have profoundly impacted the lives of many students since it's implementation in Ontario schools in the year 2001. Critics believe that students from racialized groups, in particularly Black, Tamil, Aboriginal and Latino were dealt with more harshly than other students when punishment was administrated for identical offences (Ontario Human Rights Commission 2004). There is also an indication that discipline measures have had a discriminatory effect on Black students, which has resulted in their suspensions being for more "subjective" offences. For example "being disrespectful or questioning authority," can constitute grounds for suspension of a student however there is much more latitude for "racial stereotyping and bias to enter into the decision making process" (Ontario Human Rights Commission 2004:6). It is also worth noting that research "in the United Kingdom ... confirms that Black students of Caribbean origin are disproportionately impacted by the application of discipline in schools" (London: The Runnymede Trust, 1999; Ontario Human Rights Commission 2004:5). These findings are startling but not surprising since they closely resemble many of the negative media images of Blacks as criminals or troubled youth. In addition Afro-Caribbean male students from Dei's study had also mentioned that they were viewed as "trouble makers" by schools and felt they were being judged based on socially constructed stereotypes. As a result of the many complaints that were filed by parents (representing racialized groups and children with disabilities) to the Ontario Human Rights Commission Bill 81, the province Safe Schools Act was scraped in all schools as of February 2008. 
Likewise, the government's decision to discontinue the use of Bill 81 in Ontario schools is a step closer in improving the current education system. However to further facilitate this process schools need to provide a more equitable environment for all students to succeed through the implementation of the following initiatives in Toronto Schools but as well as school boards across Canada (especially the major metropolitan areas):

a Diversifying teaching staff, counsellors, and administrators, is critical to reach students of all backgrounds and therefore students can see themselves in a successful position

- Provide students with various perspectives and materials that do not merely reinforce Eurocentric standards, therefore creating an inclusive classroom

a Work collaboratively with parents and educators-schools must recognize that in order to achieve student success, they must view parents as valued partners

- Schools must prepare students to participate in society-they must recognize and respect diversity as a valid part of their "community" definition

- Equip teachers with diversity training, including how to handle sensitive issues in the classroom

- Have professionals from various cultural backgrounds come in to speak about their jobs and experiences at a career fair

- Provide settlement workers for schools with high immigrant populations

a Honour cultural diversity and religious beliefs

a Regularly schedule University, College, and Skill Trades school fairs to keep afterschool goals in students' minds

Even though the above recommendations have been made it is not to say that this issue can be easily resolved through the implementation of a few policy initiatives. But by acknowledging that racism exist, in schools and how it can be combated may in fact contribute to minimize the effects of such complex forms of racism which have manifested itself within the education system and strictly impacted racialized groups. Through this process school environments that engage the vast majority of the student body would be created since students will be able to see themselves reflected in the curriculum and staff, as well as their parents and community would now be viewed as equal partners working together for the academic successes of their children. Therefore the above initiatives can serve as an initial start to beginning the process of creating an equitable education system that will have a definite impact on the AfroCaribbean and Portuguese communities and on the lives of the student population on a whole. This will lead in the academic achievement of all students being increased and they will become positive role models for younger students in their communities and beyond. 
Finally the school environment continues to alienate students belonging to racialized groups in comparison to those individuals from ethno cultural groups such as the Portuguese. The teaching and administrative staff needs to be diversified in order to reach students of various backgrounds (Brampton Guardian 2007). As a result, the current teaching profession "colours" the way that students view success by having a homogeneous staff, which reinforces the subordinate position that Afro-Caribbean youth occupy in the school system (Brampton Guardian 2007).

Data gathered from the 1991-92 period indicated that 55 percent of Canadian born Black students believes their school treats students of all races and ethnic backgrounds fairly and equally while 65 percent of Caribbean-born Blacks differed a bit but were still quite negative in comparison to other cultural groups (Cheng, Yau \& Ziegler 1993:26). This later point can be demonstrated through the same study whereby 78 percent of Portuguese students supported the above view (Cheng, Yau \& Ziegler 1993:18). The difference in opinions between Black and Portuguese students can be largely attributed to the fact that Portuguese belong to a White group whereas Blacks form another group (despite their country of origin) whom are constantly reminded of their foreign position through their daily encounters with authority figures (teachers, administrators, and support staff) in the school system (Cheng, Yau \& Ziegler 1993). Although Portuguese students may not share the same language or cultural beliefs as teachers they still do not come under the same surveillance as Blacks and other racialized groups in the school system due to their ability to physically blend in with the host culture. Further confirming this argument is the fact that 37 percent of Black Canadian born students felt comfortable talking to teachers about school related work (Chen \& Yau 1999:17). However in the same study it was found that all other White groups except Portuguese and Greeks ranged in their level of comfort from 47 percent to 56 percent (Jewish). Only amongst Portuguese 42 percent and Greek students 43 percent were the numbers low (Chen \& Yau 1999:39). This could be closely related to the ethnic identity that these students share, which makes them feel self conscious about their abilities and therefore less likely to seek extra help from teachers. Some of the other groups such as Jews and Italians are well established and represented in all facets of society (i.e. political and social institutions) therefore they feel some sense of entitlement to request assistance from their teachers. 
Next, in the same study 55 percent of Afro-Caribbean students were reported to have said they feel a sense of belonging "all the time" or "often" while 61 percent of Portuguese students supported the same statement (Cheng \& Yau 1999:37-38). Similarly the same study also indicated that 48 percent of Afro-Caribbean students said they enjoy school while 42 percent of Portuguese students held this view (Cheng \& Yau 1999:37-38). It is quite apparent that Black students have developed a much stronger sense of alienation is comparison to their Portuguese counterparts. Due to their more visible status and their inability to connect with authority figures Blacks find there overall school experience disappointing. However it is very interesting to note that Portuguese students enjoyed the school experience even less than Afro-Caribbean students. This could be attributed to some facts that were referenced earlier chapters such as the English language not being the mother tongue of many Portuguese students so therefore it makes the schooling experience fairly difficult to complete daily home work and assignments.

\subsection{NON-RACIALIZATION}

In contrast to the anti-black racism that Afro-Caribbean youth are confronted with in Toronto high schools it is quite apparent that the majority of Portuguese students have not experienced the full impact of this specific barrier since they belong to a non-racialized group and may choose to identify themselves by the virtue of their ethnicity. However the position that Portuguese youth occupy in society can partly be attributed to some of the strong cultural values that exist within the community that have contributed to the construction of their "societal image." These negative stereotypes have spilt over into the education system and added to the low expectations that teachers may have of Portuguese students, which continues to dictate their working class status and the type of employment that they can obtain. Data from the Toronto Board collected in the 1991-92 period support the above claim since only 53 percent of all Grade 9 Portuguese students were taking Advanced level courses and they compromised the second highest proportion of learners in the Basic stream, next to Aboriginals (Royal Commission 1994).

Furthermore upon close examination of the Portuguese community's presence in Canada in relation to early immigration policy (prior to 1967) it is quite clear that they gained admission into the country based on their relationship to the concept of "whiteness." Even though such groups as Portuguese Italians and Greeks were frowned upon by Canada's founding nations- 
Britain and France it was believed that with time these groups would be ethnically cleansed and assimilate to Canadian culture. Therefore this concept of "whiteness" has a certain "elasticity" that can be extended to other European nationalities without the threat of compromising the “...basic fabric of white entitlement" (Brand 1994:188).

As a result of their advantageous position such groups as the Portuguese were able to access certain privileges once they gain entry to the country such as the "Canadian identity, nationality and citizenship" whereas new comers mainly from racialized groups are required to complete complex screening processes in order to gain these basic rights and even when they do their still not viewed as Canadians (Brand 1994:187). Brand (1994) also points out that most often the commentary and letters that are read in daily newspapers are "largely from these coopted groups, decrying 'people who come to Canada should just become Canadians' or 'When I came to this country there was no multiculturalism, you could not expect a grant or anything, you just had to fit in." (p. 188). This example clearly illustrates that gradually over time one can forget their ethnic identity and adopt or slip into "whiteness" which ultimately coincided with the objective of Canada's all "White" immigration policy (Brand 1994). Further reinforcing their fortunate status in society Nunes (2003) points out that:

The Portuguese in Canada do not experience conflictual relations with either the mainstream or with other ethno racial minorities. They are generally regarded as hard working, peaceful and generally content with their situation in their new land. They also do not normally report being victims of the same hostility or scorn, that is often described by the members of some visible minority groups. For example, in one study conducted by a Toronto newspaper in the 1980s, the Portuguese were one of the few groups which did not complain about discriminatory treatment (Toronto Star, 1985) (p. 130).

On the other hand, youth mainly from the Portuguese community have argued that they are excluded as a target group for "affirmative action" and "anti-racist" initiatives, which they believe to be unfair (Nunes 1998:32). Some youth also alluded to the fact that Portuguese Canadians suffer from many of the same issues that non-white groups face such as access to education and their parents status as low incomes earners (Nunes 1998). In addition, Portuguese youth would like to be included in anti-racism and equity initiatives, which would better, facilitate students whose plans are to seek employment in professional careers (i.e. doctors, teachers) and gain entrance to various college and university programmes (Nunes 1998). Subsequently youth from the Portuguese community feel strongly that all of these circumstances 
should be taken into consideration and qualify them for these programmes. However these programmes are designed for racialized groups that occupy a disadvantaged position due to systemic barriers, which have inhibited their natural growth and progression in society. This is not the case for youth in the Portuguese community. As mentioned before they are not being disqualified from better opportunities by virtue of the discrimination of others; but based on their levels of educational attainment which excludes them from obtaining employment in certain professions.

Next another factor that has significantly contributed to their working class status in society stems from the fact that many members still live and work in areas/places that are predominately Portuguese speaking. For instance, a respondent from Brown's (2006) article that appeared in the Toronto Star had this to say:

[The] tight-knit nature-in which it is possible to live and shop in Portuguese neighbourhoods and work on predominantly Portuguese job sites without ever needing to speak much English-plays a role in keeping children in the same footsteps as their parents (p. 3).

The above quote demonstrates that the formation of ethnic enclaves may indeed provide a number of benefits but can result in many consequences. The intergenerational pattern of skill/semi-skilled labour is evidently passed on to Portuguese children through this process and prevents them from liberating themselves from their working class status. Likewise Bassani, who works with the Toronto Catholic School Board states that "parents work two, three jobs, and they don't necessarily trust institutions like schools; they don't understand how they work and they don't want to challenge authority, so they stay disengaged" (Brown 2006:3). Therefore the position that Portuguese parents, retain in society is essentially due to the type and terms of there employment and their lack of knowledge of the school system, that functions as a barrier, and continues to dictate the lives of their children.

\subsection{NEGATIVE STEREOTYPING}

When the experiences of Afro-Caribbean youth are compared to Portuguese students it is evident that they have not been disadvantaged by this barrier on the basis of racial characteristics but through negative stereotypes that have played a pivotal role in the experiences of Portuguese youth. A respondent from Henry's study (1994) suggested that this problem not only affects Caribbean students "...but generally the immigrant community - West Indians, Greeks, 
Italians, Portuguese - because White folks don't treat the Mediterranean folks as White folks, you know" (p. 135). This view also supports the Royal Commission (1994) findings, which indicated that Portuguese students are streamed into non-university courses. This is also conveyed through the sentiments of a former student in Toronto:

When I first came to Canada, what the school did to me was incredible. Because I didn't know how to speak English, they [the school] put me in the General level... ...I started getting really high marks... ...I tried to go on to the Advanced... ... They told me I had to start all over again... ... So I repeated grade 9 with all General, then I repeated grade 9 with all Advanced, before I could move on... ... I graduated, I think with 52 (credits)......And then, at graduation they gave me a best achievement award (Nunes 1998:31).

Equally important to note is that Portuguese youth are more inclined to dropout from high school than other White students who study in General and Basic level courses and are not likely to plan for university. In addition 39 percent of Portuguese students are enrolled in general level courses, which accounts for at least one-third of their population enrolled in this specific stream (Cheng, Yau \& Ziegler 1993:25). While further reports show that Portuguese students retain the highest percent ( 9 percent) of students in Basic level courses amongst Whites (Cheng, Yau \& Ziegler 1993:36). There is also a huge gap that exists between Portuguese students enrolment in the sole academic stream ( 52 percent) in comparison to other "White" students that identified themselves as Jewish (95 percent) or English ( 81 percent) correspondingly (Cheng \& Yau 1999:14). Finally, data from the TDSB reveals that Portuguese students receive 35 percent of their awards in sports, which is one percentage higher than that of Afro-Caribbean youth (Cheng \& Yau 1999:39). Clearly Portuguese students face many of the problems that black students have encountered from this particular barrier. However these negative stereotypes are not racially driven or saturated in media images but have been ingrained in the minds of many people from the Portuguese community and society at large. For example, one person stated in Nunes' (1998) study that, "they [the Portuguese] accept perfectly the fact that they are only construction workers and cleaners, and they live within this stigma perfectly content" (p. 35). This mindset has mainly been associated with first generation migrants settling in Canada that continue to construct their daily lives (and even their children's existence) based on principals that were established in the home country and the employment opportunities that were made readily available to them (skilled or semi-skilled labour) once they had arrived in the country. Although it should be noted that the potential for assimilation for "white" Portuguese students is 
an option that the majority have not chosen because their pride to retain their culture and language has greatly contributed to their reluctance to assimilate and "just" become "Canadians."

\subsection{SCHOOL ENVIRONMENT}

Finally Portuguese youths positioning in the school system is slightly different from that of Afro-Caribbean students. They see others that share similar physical characteristics but may not identify with these individuals by way of ancestry, culture, religion, and language due to their ethnic status (Alladin 1996). Therefore this particular barrier does not seem to have an adverse affect on students but parents would like to see more Portuguese-speaking teachers in schools (Royal Commission 1994). This would greatly benefit many Portuguese youth by having teacher role models from their community working, as "professionals" in schools, which would demonstrate that they have made it in "non-traditional" career paths.

In the same way the Portuguese communities' social reproduction, as a predominately working class community has increasingly been cited as a barrier to their "effective integration" in society (Nunes 2003:129). For the most part their ineffective incorporation in society stems primarily from the lack of representation of highly educated professionals in the Portuguese community. These professionals would possess political and economic influences that are crucial to pressure governments for resources that can resolve community problems and create effective discourse between middle class members of "mainstream Canadian society" (Nunes 2003:129). Therefore the communities "high degree of occupational segregation" serves their working class status and continued isolation from society at large (Nunes 2003:129).

Also at the root of their continued isolation is the fact that many Portuguese value the preservation of their language and culture since they view these as key features of their ethnic identity. This practice can be observed through the following comments made by Arruda, who is a member of the new Portuguese-Canadian Education Network "as a community, we're proud of our ability to preserve our culture-but this is Canada! We have to nail down English! We have to create an environment that expects children to succeed at school" (Brown 2006:2). Directly related to their concern of language and cultural preservation is the prevalence of some children from the second and even third generation who speak fluent Portuguese "or a mixture of Portuguese and English, sometimes referred to as "portingles" which has posed some problems in their successful integration in schools (Cabral: 1996; Nunes 2003:138). These children have 
been reported to be misplaced in a school system that interprets their "language difficulties" as being intellectually deficient or learning disabled (Nunes 2003). To some extent Portuguese youths language difficulties have been a huge impediment in their placement in the appropriate academic streams as well as contributing to many of the low expectations that teachers maintain.

Unquestionably all of the above factors have contributed to Portuguese youths alienation. The fact that children are unable to develop the appropriate language skills to better negotiate the Canadian middle class school system poses a problem. This is closely related to the fact that some Portuguese parents choose to use grandparents as childcare providers since "they know and trust" these individuals, however Bassani from TCDSB also points out that "there is no real culture of literacy being built around the kitchen table" to encourage suitable language acquisition skills (Brown 2006:3). This tendency can be attributed to many first generation Portuguese-Canadians who became preoccupied with their "family projects" (i.e. purchasing a home) which prevented their active participation in the cultural, civic, and political realms of mainstream Canadian life (Nunes 2003:145). As a result of their circumstances PortugueseCanadians "passive fluency" in English (a result of their low educational levels) and very little knowledge of Canada, led to their increased dependency on their family which caused them to detach themselves and even more so their children from the school system (Nunes 2003). This tendency to distance themselves from the rest of society can be heard through the following account, stated by Brum who is a counsellor with the TDSB:

Portuguese parents must learn to "shop around" for the high school that best prepares their child with a full range of programmes, not necessarily just the closest school or the one with the most Portuguese students (Brown 2006:1).

This specific tendency amongst parents to enrol their children in schools with predominately Portuguese students may provide some relief and comfort for parents but has its disadvantages. One major disadvantage is that this type of setting would impact Portuguese students negatively since the school is predominately Portuguese therefore youth from the community are unable to gain confidence in the development of their English language ability because there is no need to speak English with peers. As noted earlier many Portuguese children learn to speak their mother tongue prior to entering school as a result it may be much easier to communicate in Portuguese with peers than English. This issue is also demonstrated in the subsequent example, "at St. Helen Catholic School in Little Portugal, ... 89 percent of students 
were born in Canada, yet for 61 percent, and the first language they learned at home was not English" (Brown 2006:3). The quote implies that this practice continues up until this moment in the Portuguese community, which undeniably has made the classroom experiences of children a challenging and difficult process.

As a result of Portuguese students language difficulties they have encountered numerous problems effectively negotiating the school system. In a report from the Royal Commission (1994) some of the speakers disputed that students requiring support in English (and Portuguese) language training should not be withdrawn from regular classes to participate in these special programmes that are designed to facilitate improvement in their English proficiency level (p. 10). This remains a concern of many but it is also worth noting the fact that 67 percent of Portuguese students were confident in their oral skills meanwhile other students who identified as "White" survey responses ranged from 73-75 percent (except for 61 percent of Polish students whom more than half (68\%) had arrived in the country since 1987) (Cheng \& Yau 1999:43). However only 50 percent felt the same way about their writing skills, which was the lowest amongst the "White" category where the responses ranged from 58-70 percent (Cheng \& Yau 1999:43). This trend can also be observed by examining data from Cheng \& Yau (1999) who reported that Jewish, Greek, East Indian and Canadian-born Blacks were more likely to aspire for careers in teaching or law because they demonstrate higher levels of confidence in such skills as communication (p. 33). These statistics are not surprising given the fact that many parents and community members have cited that language and cultural preservation is a key component of maintaining the Portuguese identity. In addition it is this strong commitment to their cultural identity that has resulted in the communities' limited fluency in English and lack of highly educated professionals, which has led to their continued working-class status in society. Likewise the Portuguese communities own social reproduction has become intergenerational and is passed on to their children who are challenged by these barriers in schools and society at large. 



\section{CONCLUSION}

It is quite clear that racism is not only a historical feature of the deep south of the United States. It is alive and well in Canada. Government policies have gone from being overtly racist to masking the subtleties of racism within laws and practices that offer a false impression of inclusion, such as Canada's multicultural policy. Even though there were no direct references made to these policies, they are nevertheless apparent through a number of educational programs, such as Black history month. Many parents from the community feel programs such as Black History month only promote the celebration of food, song, and dance and fail to address the real issues that many racialized groups face in Canada such as racism and social inequalities. Lind states (1974) "the fact that multiple cultures in Toronto are alive is a tribute to their own resilience rather than to the system with which they co-exist" (p. 55).

In the same manner the systemic racism of past immigration policy has an adverse impact on the process of Afro-Caribbean community formation and permanent settlement through recruitment strategies that were used to attract people for specific jobs, which in turn determined their social status and family organization. All of the above factors apply to the Portuguese community as well, except for racism. Rather it was their relationship to whiteness, which gained them earlier entry to the country and access to certain privileges that most racialized groups were denied up until 1967.

It is then through the system of these founding groups that the power of racism is revealed and the role it plays in dictating how Black students 'negotiate' their way through the education system can be observed through an examination of the five dimensions of racism, which have operated as a barrier in the academic success of Afro-Caribbean students in Toronto high schools. The experiences of Portuguese students in schools are quite different than those of Afro-Caribbean youth since they are from an ethno cultural group and can assimilate over some period of time and eventually gain acceptance and access to certain privileges due to their relationship to whiteness. Therefore the even greater rate at which Portuguese students drop out of high school, when compared to Afro-Caribbean students, may only be temporary and the case 
of a one-generation immigrant adjustment factor since their academic performance is not affected by the robustness of racism in the system as with their Afro-Caribbean counterparts. Instead, their problems can be attributed to some of the educational inequalities that have disadvantaged them in the schooling process.

Afro-Caribbean and Portuguese youth are disproportionately dropping out of school or being streamed into general or basic level classes, which are now identified as "applied" or "workplace essentials" classes under the new curriculum, which came into practice in 1999. Parents of both communities come from various class levels and have obtained varying levels of education, but there is considerable disparity between the communities at higher educational levels. Notably the parents of Portuguese youth have lower levels of education than the parents of Afro-Caribbean children. These differences can be partially attributed to the time period that each group migrated to Canada, which was reflective of the labour market trends that were in demand as well as the specific selection criteria of immigration policy, and partially to the different values the two communities place on education. Higher education, and what it takes to get there, is not prized in the Portuguese community the way it is in the Black community in general and the Afro-Caribbean community in particular. The Afro-Caribbean community has a greater commitment to deferred gratification; the Portuguese community has a focus on getting well-paying jobs of whatever sort as early as possible in life, and doesn't see the point of deferred gratification. In the case of the Portuguese it was unskilled manufacturing jobs that drew them, and for Afro-Caribbean people it was the point system, which judged individuals based on their education, credentials, and entrepreneurial skills - race was not a factor. Even though the main reason that people migrate to Canada is to seek better opportunities for themselves and even more so for their children, different groups may define "success" differently. Nevertheless, the children in these two groups are not successful in the school system, and at least part of the reasons why they are performing quite poorly is due to their lack of social capital and the systemic barriers that they face. It is also quite evident that the past and current teaching practices of the TDSB have affected ethno cultural groups such as the Portuguese to drop out at an even higher rate than Afro-Caribbean youth. This particular phenomenon will continue unless the education system is restructured and reflective of the diverse student population that attends Toronto high schools. 
In light of current and future immigration trends it is apparent that schools will have to be restructured in order to meet the demands of such a diverse population. Therefore the following research recommendations can be made with regards to the collection of data in the TDSB. Firstly, it would be beneficial to differentiate between the academic performance of males versus females in both the Afro-Caribbean and Portuguese communities. This type of research should also note whether there are significant differences in the drop out rates reported amongst Black males versus females since it has been noted in current research that Afro-Caribbean males come under the most surveillance when compared to other groups of males. Next, with regards to the TDSB student surveys and data collection the Canadian born Black students category needs to be broken down to differentiate between Black Canadians that have been in the country for generations versus second-generation Caribbean. This would help provide a more accurate analysis of whether are not there is any variation in academic performance amongst students that there families have been here for generations when compared to recent immigrants. There also needs to be more research done in the area of second-generation Caribbean students that are now adults and investigate whether or not they have improved their social status in society when compared to their first generation parents or has the racism in the school system kept them from improving their position. This type of research would indicate or provide information on how the racism encountered in the system has help determine their lives once they have left school. Finally, more in depth studies are needed of Portuguese students' personal experiences in the TDSB. This would provide detail descriptions of the challenges that they have encountered but from their viewpoint similar to the type of research that was discussed of Afro-Caribbean students. Addressing this particular research gap would give further insights to the issues Portuguese students come upon in the school system. 



\section{APPENDICES}




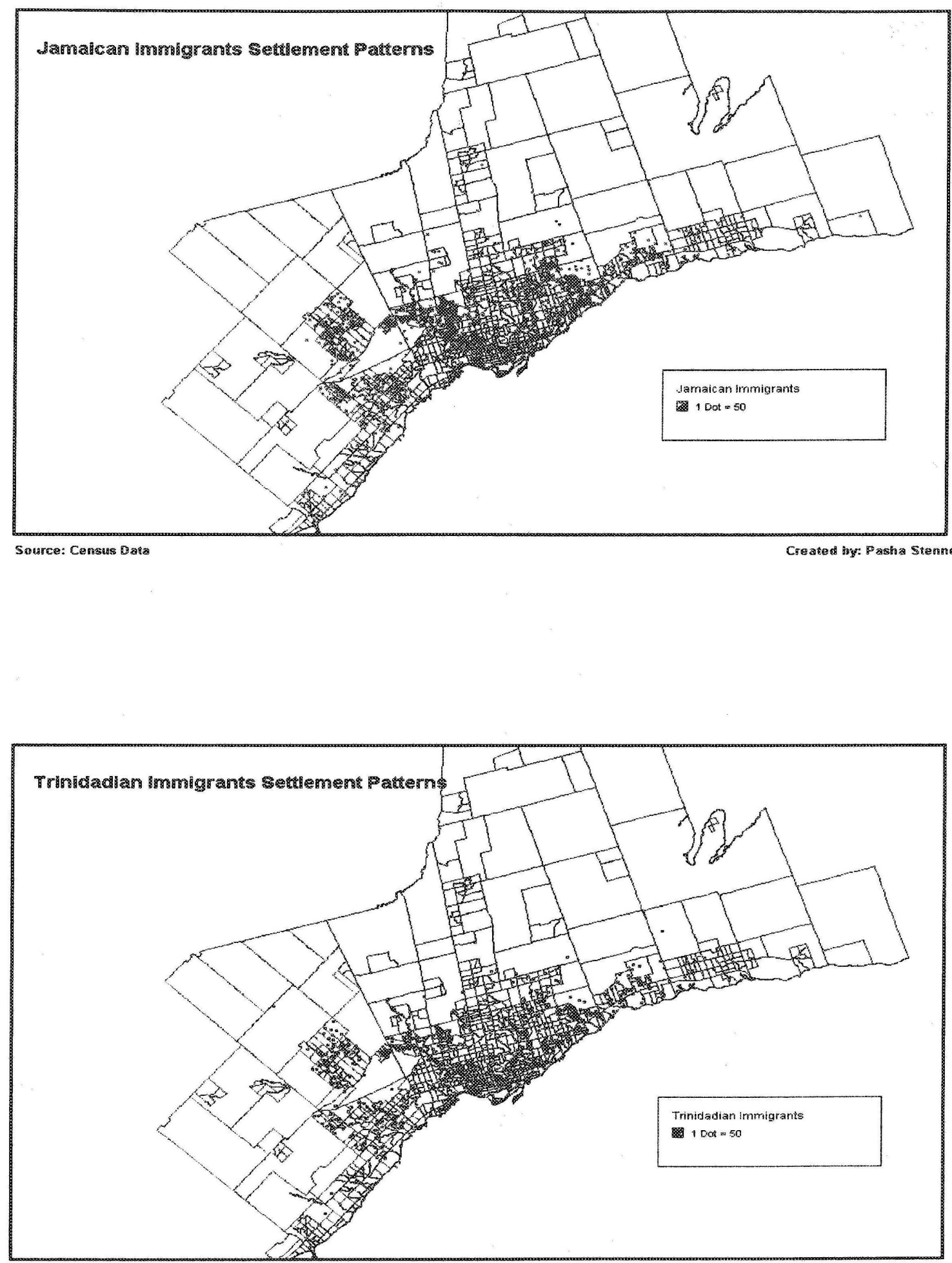

Source: Census Data

Created ty: Pasha Stennetr 


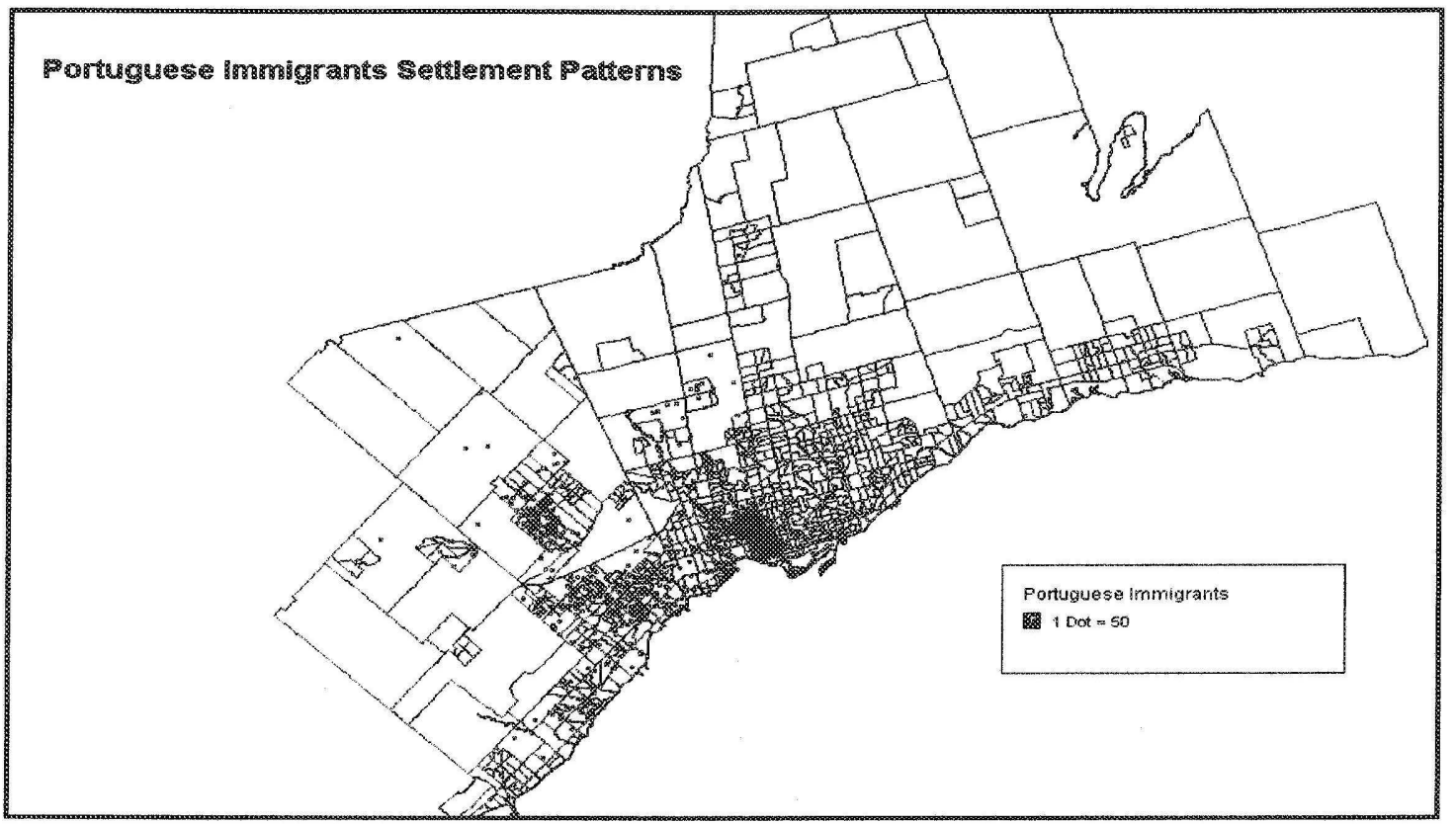

Ssurce: Consess Data

Created an: PPasc Sterngn 


\section{REFERENCES}

Aguiar, L. (2006). The New "In-Between" People: Southern-European Transnationalism. In V. Stazewich and $\mathrm{L}$. Wong (Ed.), Transnational Identities and Practices in Canada. UBC Press, pp. $202-215$.

Alladin, I. (1996). Racism In Schools: Race, Ethnicity, and Schooling in Canada. In I. Alladin (Ed.), Racism in Canadian Schools. Toronto Canada Cambrian, College: Harcourt Brace \& Company Canada, Ltd., pp. 4-13.

Arat-Koç, S. (1997). From Mothers of the Nation to Migrant Workers. In A. Bakan and D. Stasiuis (Ed.), Not One of the Family: Foreign Domestic Workers in Canada. Toronto: University of Toronto Press, pp. 53-79.

Belgrave, Roger (2007, February 16). Schools working to embrace diversity. The Brampton Guardian, pp. 15-16.

Brand, D. (1998). Bread Out of Stone. Vintage Canada.

Brown, L. (2006, December 7). Forging a new path: A new coalition in the Portuguese community wants to turn low post-secondary grad rates around. Toronto Star, p. R. 12. Retrieved April 7, 2007, from ProQuest (1175329321).

Burman, J. (2002). Remittances; Or Diasporic Economies of Yearning. Small Axe: A Caribbean Journal of Criticism, pp. 23-49.

Calliste, A. (1996). African Canadians' Organizing For Educational Change. In K. S. Brathwaite (Ed.), Educating African Canadians. Toronto: James Lorimer \& Company Ltd., pp. 87-105.

Calliste, A. (1993-94). Race, Gender, and Canadian Immigration Policy: Blacks from the Caribbean, 1900-1932. Journal of Canadian Studies, 28(4) (Winter), pp. 131-148.

Calliste, A. (1991). Canada's Immigration Policy and Domestics from the Caribbean: The Second Domestic Scheme. In J. Vorste (Ed.), Race, Class, and Gender: Bonds and Barriers. Toronto: Garamound Press, pp. 136-169.

Canadian Press. (2007, March 13). Population profile. Toronto Star, p. 1. Retrieved August 17, 2008, from http://www.thestar.com/News/article/191240

Celebration of Portuguese Heritage Act, 2001, S.0. 2001, c. 22. (2004). Queen's Printer for Ontario, pp. 1. Retrieved July 16, 2008, from http://www.canlii.org/on/laws/sta/2001 c.22/20030812/whole.html

Cheng, M. and Yau, M. (1999). The 1997 Every Secondary Student Survey: Detailed Findings, (report \#230). Toronto District School Board. 
Cheng, M., Yau, M. and Ziegler, S. (1993). The 1991 Every Secondary Student Survey, Part II: Detailed profiles of Toronto's Secondary School Students (report \$204). Toronto: Research Services, Toronto Board of Education.

Cheng, M., Yau, M. and Ziegler, S. (1993). The 1991 Every Secondary Student Survey, Part III: Program Level and Student Achievement (report \#205). Toronto: Research Services, Toronto Board of Education.

Citizenship and Immigration Canada. (2005). Retrieved November 16, 2007 from http://www.cic.gc.ca/english/monitor/issue10/05-overview.html

Citizenship and Immigration Canada. (2004). Evaluation of the Language Instruction for Newcomers to Canada (LINC) program. Retrieved July 20, 2008, from http://www.cic.gc.ca/ENGLISH/resources/evaluation/linc/exec-summary.asp

Citizenship and Immigration Canada. (1999). The Live-in Caregiver Program: Information for employers and Live-in Caregivers from abroad. Minister of Public Works and Government Services.

Codjoe, H. M. (2001). Fighting a 'Public Enemy' of Black Academic Achievement-the persistence of racism and the schooling experiences of Black students in Canada. Race Ethnicity and Education, 4(4), pp. 343-375.

Cohen, R. (1994). A brief history of racism in immigration policies for recruiting Domestics. Canadian Woman Studies, 14(2) (Spring), pp. 83-86.

Crawford-Brown, C. (1999). Who will save our children: The plight of the Jamaican child in the nineties. Kingston: University of the West Indies Canoe Press.

Crawford, C. (2003). Sending love in a barrel: the making of transnational Caribbean families in Canada. Canadian Woman Studies, 22(3/4), 1-11.

Dei, G. J. S., Mazzuca, J., Mc Issac, E., and Zine, J. (1997). Reconstructing 'Drop-out' A Critical Ethnography of the Dynamics of Black Students' Disengagement from School. Canada: University of Toronto Press Incorporated.

Dei, G. J. S., Holmes, L., Mazzuca, J., Mc Issac, E., and Campbell, R. (1995). Drop-out or Push Out? The Dynamics of Black Students' Disengagement from School. Ontario: Ministry of Education and Training.

Domingos, M. and Medeiros, J. (1980). Portuguese Immigrants: 25 Years In Canada. Toronto: West End YMCA.

Gabriel, C. (2006). A Question of Skills: Gender, Migration Policy and the Global Political Economy. In K. v. d. Pijl, L. Assassi and D. P. Wigen (Ed.). Global Regulation: Managing Crises After the Imperial Turn. Palgrave Macmillan, pp. 162-176.

Grittens M., Cole D., Williams T., Sri-Guggan S., Tam M., and R. (1995). Report of the Commission on Systemic Racism in Ontario Criminal Justice System: A Community Summary. Toronto: Queen's Printer for Ontario. 
Hawkins, F. (1989). Critical Years in Immigration: Canada and Australia Compared. Kingston and Montreal: McGill-Queen's University Press.

Henry, F. (1994). The Caribbean Diaspora in Toronto: Learning to Live with Racism. Toronto: University of Toronto Press Incorporated

Jakubowski, M. L. (1999). Managing Canadian Immigration: Racism, Ethnic Selectivity, and the Law. In E. Comack (Ed.), Locating Law: Race, Class, and Gender Connections, pp. 98-124.

James, C. E and Brathwaite, K. (1996). The Education of African Canadians Issues, Contexts, and Expectations. In K. S. Brathwaite (Ed.), Educating African Canadians. Toronto: James Lorimer \& Company Ltd., pp. 13-31.

Kilbride, K. M. and Anisef, P. (2001). To Build on Hope: Overcoming the challenges Facing newcomer youth at risk in Ontario. Report to the Ontario Administration of Settlement and Integration Services of the Department of Citizen and Immigration Canada. Toronto: Citizenship and Immigration Canada.

http://atwork.settlement.org/sys/atwork library detail.asp?doc id $=1002767$

Kilbride, K. M. (2000). A Review of the Literature on Human, Social and Cultural Capital of Immigrant Children and Their Families with Implications for Teacher Education (No. 13). Toronto: CERIS Working Paper Series. Retrieved February 21, 2007, from http://ceris.metropolis.net/Virtual\%20Library/education/WK $\% 2013$ Kilbride.pdf

Lind, L. J. (1974). The Learning Machine; a hard look at Toronto Schools. Toronto: the Canada Council and Ontario Arts Council.

Nunes, F. (2003). Chapter 7: Marginalisation, social reproduction and academic underachievement: the case of the Portuguese community in Canada. In G. D. Abreu, T. Cline, \& H. Lambert (Ed.), The Education of Portuguese in Britain: Insights from Research and Practice in England and Overseas. University of Luton: Department of Psychology, pp. 122-156.

Nunes, F. (1998). Portuguese-Canadians from Sea to Sea: A National Needs Assessment. Toronto: Portuguese-Canadian National Congress.

Ontario Human Rights Commission. (2004). Toronto District School Board Safe and Compassionate Schools Task Force. Retrieved March 13, 2008, from http://www.ohrc.on.ca/en/resources/submissions/SubmSafeSch/pdf

Plaza, D. (2003). Unpacking the Migration and Settlement Story for Indo and African-Caribbean migrants in Canada. Paper Prepared for the International Conference on Migration in the Americas: Emerging Issues York University, Canada, pp. 1-28. Retrieved April 6, 2007, from http://www.yorku.ca/cerlac/migration/Dwaine_Plaza.PDF

Prince, A. (1996). Black History Month A Multicultural Myth or "Have-Black-History-Month-Kit-WillTravel". In K. S. Brathwaite (Ed.), Educating African Canadians. Toronto: James Lorimer \& Company Ltd., pp. 167-178.

Royal Commission on Learning. (1994). For the love of leaming: Report of the Royal Commission on Learning (Vol. IV Making it happen). Toronto: Queen's Printer for Ontario. 
Satzewich, Vic. (1989). Racism and Canadian Immigration Policy: The Governments View of Caribbean Migration 1962-1966. Canadian Ethic Studies, 21(1), pp. 77-97.

Simmons A. and Plaza D. (2006). The Caribbean Community in Canada: Transnational Connections and Transformations. In Stazewich and L. Wong (Ed.), Transnational Identities and Practices in Canada, UBC Press, pp. 130-149.

Solomon, P. R. (1996). Creating An Opportunity Structure For Blacks And Other Teachers Of Colour. In K. S. Brathwaite (Ed.), Educating African Canadians. Toronto: James Lorimer \& Company Ltd, pp. 216-233.

Spence, C. M. (1999). The Skin I'm In Racism, Sports and Education. Halifax, Nova Scotia: Fernwood Publishing.

Teixeira, C. (2000). On the Move: Portuguese in Toronto. In C. Teixeira and V. M.P. Da Rosa (Ed.), The Portuguese in Canada: From the Sea to the City, pp. 207-220.

The Official Site of the Universal Negro Improve. (2007). Marcus Garvey Quotes. Retrieved August 26, 2008, from http://www.unia-acl.com/quotes.html 